Volume 15 - Número 2 - ago/dez de 2020

\title{
A CIÊNCIA DA LEITURA E SUAS IMPLICAÇÕES EDUCACIONAIS
}

\author{
Mark S. Seidenberg \\ Departamento de Psicologia, Universidade de Wisconsin-Madison (EUA) \\ Rosângela Gabriel ${ }^{1}$ \\ Débora Ache Borsatti ${ }^{2}$ \\ Alan Ricardo Costa ${ }^{3}$ \\ Kadine Saraiva de Carvalho ${ }^{4}$ \\ Nicole Petry Rieger ${ }^{5}$ \\ Matheus da Costa Tatsch ${ }^{6}$
}

\begin{abstract}
Research in cognitive science and neuroscience has made enormous progress toward understanding skilled reading, the acquisition of reading skill, the brain bases of reading, the causes of developmental reading impairments and how such impairments can be treated. My question is: if the science is so good, why do so many people read so poorly? I mainly focus on the United States, which fares poorly on cross-national comparisons of literacy, with about $25-30 \%$ of the population exhibiting literacy skills that are low by standard metrics. I consider three possible contributing factors, all of which turn on issues concerning the relationships between written and spoken language: the fact that English has a deep alphabetic orthography; how reading is taught; and the impact of linguistic variability as manifested in the Black-White "achievement gap." I conclude that there are opportunities to increase literacy levels by making better use of what we have learned about reading and language but also institutional obstacles and understudied issues for which more evidence is badly needed.
\end{abstract}

RESUMO: A pesquisa em ciência cognitiva e neurociência tem feito um enorme progresso em direção à compreensão da leitura hábil, da aquisição de habilidades de leitura, das bases cerebrais da leitura, das causas do desenvolvimento de dificuldades na leitura e de como elas podem ser tratadas. Minha pergunta é: se a ciência é tão boa, por que tantas pessoas lêem tão mal? Eu me refiro principalmente nos EUA, que apresentam baixos resultados nas comparações internacionais de alfabetização, com cerca de 25 a $30 \%$ da população exibindo habilidades de leitura que estão abaixo da média. Considero três possíveis fatores que contribuem para este quadro, todos envolvendo questões relacionadas às relações entre a língua escrita e a língua falada: o fato de a língua inglesa ter uma ortografia alfabética opaca; a forma como a leitura é ensinada; e o impacto da variação linguística manifestada na diferença de desempenho entre negros e brancos ${ }^{7}$. Concluo que é possível elevar os níveis de alfabetização aproveitando melhor

1 Doutora em Letras / Linguística (PUCRS) com doutorado-sanduíche no Departamento de Psicologia Experimental da Universidade de Oxford / Inglaterra. Professora e pesquisadora do curso de graduação em Letras e do Programa de Pós-Graduação em Letras (PPGL), área de concentração "LEITURA: estudos linguísticos, literários e midiáticos", da Universidade de Santa Cruz do Sul (UNISC). Orcid: https://orcid.org/0000-0002-25352497. E-mail: rgabriel@unisc.br

2 Doutoranda em Letras (UNISC) com estágio sanduíche na Universidade de Pittsburgh (EUA), bolsista Capes/Prosup. Professora na área de Letras no Instituto Federal de Educação, Ciência e Tecnologia Sul-riograndense (IFSUL). Orcid: https://orcid.org/0000-0003-1486-0047. E-mail: deborsatti@gmail.com.

3 Doutorando em Letras (UNISC), bolsista Capes. Orcid: https://orcid.org/0000-0001-8132-6202. E-mail: alan.dan.ricardo@gmail.com.

4 Mestranda em Letras (UNISC), bolsista CNPq. Orcid: https://orcid.org/0000-0002-9749-0493. E-mail: kadine@mx2.unisc.br.

${ }^{5}$ Mestranda em Letras (UNISC), bolsista Capes/Prosup. Orcid: https://orcid.org/0000-0003-3614-576. E-mail: nicolerieger12@gmail.com.

${ }^{6}$ Mestrando em Letras (UNISC), bolsista Capes/Prosup. Orcid:orcid https://orcid.org/0000-0002-5887-1664. Email:mathtatsch@gmail.com.

7 N.T.: em inglês, o autor utiliza Black-White "achievement gap", expressão consagrada nos EUA para dar conta dos efeitos das diferenças socioeconômicas históricas entre brancos e negros naquele país. 
o que aprendemos sobre leitura e linguagem, mas considerando também os obstáculos institucionais e questões menos estudadas, para as quais mais evidências são extremamente necessárias.

Há uma área nas ciências cognitivas e na neurociência cognitiva que tem sido mais bemsucedida do que o estudo da leitura? Não podemos subestimar aquilo que já foi aprendido. Nós, a comunidade de cientistas que estuda a leitura (incluindo meus colegas Perfetti e Treiman, cuja pesquisa é descrita em artigos a seguiir ${ }^{8}$ ), entendemos os mecanismos básicos que dão suporte à leitura hábil, a forma como a habilidade de leitura é adquirida e as possíveis causas de problemas de leitura.

Entendemos o problema fundamental enfrentado pelo leitor iniciante: como relacionar um novo código, um roteiro escrito, a um código existente, a linguagem falada. Sabemos quais comportamentos dos pré-leitores de quatro anos são fortes preditores da habilidade de leitura posterior, como as crianças fazem a transição de pré-leitores para leitores e os obstáculos que muitos encontram. Sabemos o que distingue leitores hábeis e leitores fracos, leitores qualificados mais jovens e mais experientes, leitores "típicos" daqueles que são atípicos devido tanto a fatores constitucionais (como problemas de audição ou aprendizado) como ambientais (por exemplo, escolaridade de baixa qualidade ou pobreza).

Sabemos como as habilidades básicas que facilitam a iniciação da criança na leitura se relacionam com outros tipos de conhecimentos e capacidades que apóiam a compreensão de textos com incremento de variedade e dificuldade. Entendemos que alguns aspectos da leitura são universais (porque os cérebros das pessoas são essencialmente parecidos) e outros não (devido às diferenças entre os sistemas de escrita e as línguas que eles representam).

Estudos com neuroimagem vêm obtendo sucesso na identificação dos principais circuitos cerebrais envolvidos na leitura e nas formas anômalas com que eles se desenvolvem nos disléxicos, bem como as várias causas prováveis de tais deficiências. Temos modelos computacionais que especificam os mecanismos subjacentes às habilidades básicas de leitura, como as crianças as adquirem e como as diferenças na experiência (com a linguagem falada e a leitura) e as diferenças individuais (nas capacidades de aprendizagem e memória, motivação e outros fatores) geram resultados variados em leitura. Essa vasta base de pesquisa levou ao desenvolvimento de métodos de intervenção que podem auxiliar muitas crianças de modo confiável. Os pesquisadores discordam em muitos detalhes - é ciência, não os Dez Mandamentos - mas há um consenso notável sobre a teoria básica de como a leitura funciona e as causas dos sucessos e fracassos na leitura (ver RAYNER et al., 2001; PENNINGTON, 2006; MORRIS et al., 2010; GABRIELI, 2009; PUGH et al., 2012).

Minha pergunta, então, é a seguinte: se a ciência é tão avançada, por que tantas pessoas lêem tão mal? Nos Estados Unidos, há pouco tempo, tivemos um "momento Sputnik" ocasionado pelos resultados de 2009 do Programa Internacional de Avaliação de Estudantes (PISA), avaliações internacionais de desempenho acadêmico de jovens de 15 anos (OCDE PISA, 2009). Conforme os anos anteriores, o desempenho dos Estados Unidos esteve próximo da média dos 34 países da OCDE. No entanto, essa rodada foi a primeira a incluir dados de Xangai e Cingapura, que, juntamente com Coréia, Hong Kong e Japão, pontuaram acima dos Estados Unidos. Esses resultados receberam muito mais atenção do que o fato de, durante muitos anos, os Estados Unidos terem pontuado menos do que países como Canadá, Austrália, Finlândia e Nova Zelândia no PISA. O presidente, o secretário de educação e o comentarista (por exemplo, FINN, 2009) trataram os resultados como evidência de uma crise na educação

\footnotetext{
${ }^{8}$ N.T.: o autor se refere a outros artigos publicados na revista científica Language Learning and Development. Endereço de contato com Mark S. Seidenberg, Departamento de Psicologia, Universidade de Wisconsin, Madison, 1202. W. Johnson Street, Madison. WI 53706. E-mail: seidenberg@wisc.edu.
} 
americana que demandava ação imediata. Porém, 2011 não era 1957 e, portanto, o segundo "momento Sputnik" passou rápido, saindo rapidamente do discurso público (Figura 1):

Figura 1

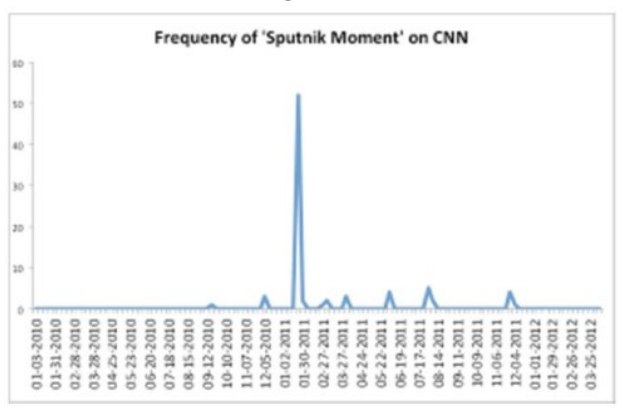

FIGURA 1: Número de vezes que a frase "momento Sputnik" foi pronunciada na CNN, uma rede americana de TV a cabo em um período de dois anos. O grande aumento ocorreu após a divulgação dos resultados da avaliação do PISA de 2009 e coincidiu com o discurso do presidente Obama sobre o Estado da União em 2011 (Figura colorida disponível online).

Apesar de os resultados do PISA terem se tornado notícia, existem muitos dados internos sobre o problema da literacia nos Estados Unidos publicados no site do Departamento de Educação (http://ies.ed.gov). A Avaliação Nacional de Literacia de Adultos (2003) constatou que cerca de 93 milhões de adultos lêem nos níveis "básico" ou "abaixo do básico". Nesses níveis, uma pessoa pode conseguir encontrar a lista de programas na TV a cabo, mas não entender as instruções e os avisos que acompanham seus medicamentos para pressão arterial (LESGOLD; WELCH-ROSS, 2012). Os resultados da Avaliação Nacional do Progresso Educacional (NAEP) ("boletim do país") documentam as origens da baixa literacia no desempenho de alunos da quarta e da oitava série (http://nces.ed.gov/nationsreportcard). Como tudo que se refere à educação nos Estados Unidos, essa avaliação tem sido foco de controvérsia, com diferentes partes interessadas mobilizando os dados em diferentes direções. Pessoas que enfatizam quão bom é o desempenho da educação americana apontam para a constatação de que, desde 1992, quando a forma moderna do NAEP foi introduzida, entre 59\% e $67 \%$ dos alunos da quarta série e $69-76 \%$ dos alunos da oitava série obtiveram pontuação de nível "básico" ou superior. Pessoas que pensam que deveríamos estar melhor - eu estou entre eles podem destacar o fato de que 66-71\% dos estudantes de quarta série e 66-71\% dos estudantes de oitava série obtiveram pontuação nos níveis "básico" ou "abaixo do básico". Em outras palavras, há muitas crianças pontuando no nível mais baixo (cerca de um terço dos alunos da quarta série e um quarto dos alunos da oitava série estão "abaixo do básico") e poucas crianças com notas mais altas (entre 6 e $8 \%$ dos alunos da quarta série e apenas 3\% da oitava série são leitores "avançados" de acordo com essa avaliação). O governo americano está em uma fase de muitas testagens e, portanto, há muitos outros dados sobre quem sabe ler e quão bem, que poderiam ser retomados aqui. Pode-se afirmar que as avaliações de adultos e crianças indicam, de forma consistente, que um grande número de indivíduos nos Estados Unidos lê mal, e isso é uma realidade há muitos anos.

As consequências da baixa literacia para os indivíduos afetados e para a sociedade são vastos, como todos sabemos. Gera sérios desafios para a plena atuação no mercado de trabalho, no gerenciamento do próprio cuidado com a saúde e no avanço da educação dos filhos. Observando esses fatos, a partir do conhecimento sobre como a leitura funciona, questiono-me se nossa ciência tem algo a contribuir para melhorar os resultados da literacia neste país e em outros. Talvez não. A falha na literacia pode estar relacionada a fatores bem fora dos limites dessa ciência, como a pobreza, por exemplo. A pobreza tem muitas sequelas, incluindo maior 
taxa de mortalidade infantil, desenvolvimento atípico do cérebro, menor tempo de vida, problemas de saúde e assistência médica, maiores índices de criminalidade e encarceramento, menor desempenho escolar, maiores taxas de evasão escolar, escolas mais pobres com professores menos experientes e, concluindo uma lista que poderia ser muito mais extensa, baixo desempenho em leitura (United States Government Accountability Office, 2007). Certamente a redução da pobreza teria um impacto maior na literacia do que qualquer ação inspirada em nossa pesquisa. Qualquer pessoa com um plano politicamente aceitável para reduzir ou eliminar substancialmente a pobreza deve apresentar-se imediatamente.

Se a pobreza fosse tudo o que importa, este artigo poderia terminar aqui. No entanto, a relação entre o status socioeconômico (SES) e o desempenho na leitura não é simples. É difícil isolar os efeitos do SES (ele mesmo um construto complexo; DUNCAN; MAGNUSON, 2005) dos demais fatores com os quais está correlacionado. Não obstante, dados de várias fontes sugerem que há muito sobre os resultados observados da literacia que o SES não explica. Esta questão será retomada na seção final deste artigo, no contexto da diferença de desempenho entre negros e brancos, em que a confusão entre o SES e desempenho é particularmente preocupante. Aqui eu quero citar algumas descobertas representativas, sugerindo que, embora a pobreza tenha um impacto enorme, ela não é a história completa.

As avaliações do PISA fornecem uma riqueza de dados (por assim dizer) sobre a relação entre a riqueza nacional e o desempenho de leitura. O conjunto de dados de 2009 inclui várias medidas relacionadas à saúde econômica de um país que é parte do grupo central de 34 países da OCDE. As principais conclusões são bastante interessantes ${ }^{9}$. Em resumo, dois fatores econômicos, o Produto Interno Bruto (PIB) do país e o valor gasto em educação, são apenas superficialmente relacionados ao desempenho da leitura. A proporção de estudantes socioeconomicamente desfavorecidos em cada país tem um impacto maior, com proporções mais altas associadas a pontuações mais baixas. No entanto, os Estados Unidos não obtêm média baixa pela alta representação dos estudantes de baixa renda; de fato, os Estados Unidos estão agrupados com muitos países da OCDE nessa medida, e as pontuações de leitura nesse grupo variam amplamente. Outro aspecto interessante é que o nível de educação dos pais é um preditor muito mais forte do que os indicadores econômicos nos vários países. Obviamente, são necessárias análises mais complexas para identificar as relações entre esses fatores e suas relativas contribuições. Não obstante, esses dados descritivos indicam que tanto o SES como outros fatores são importantes determinantes dos resultados.

A avaliação do NAEP também inclui informações sobre os efeitos moderadores de uma variedade de fatores, incluindo raça/etnia, gênero e elegibilidade para almoço escolar subsidiado ou gratuito, um indicador comum (embora impreciso) do $\mathrm{SES}^{10}$. Novamente, há fortes indícios de que ambos, SES e outros fatores, afetam os resultados. Existe um amplo, consistente efeito do SES, conforme indexado pelos dados de almoço subsidiado em todos os anos da testagem. No entanto, existem resultados semelhantes para outros fatores, como o gênero. As mulheres obtiveram pontuações significativamente mais altas do que os homens em todos os anos da avaliação NAEP. As mulheres também tiveram pontuação significativamente mais alta que os homens em todos os países/estados participantes na avaliação do PISA de 2009. (Os Estados Unidos apresentaram uma das menores diferenças de gênero, enquanto a Finlândia, um país de perene alta pontuação, obteve uma das maiores.) As diferenças de gênero intra e entre os países podem estar relacionadas, de maneira complexa, ao SES, mas a consistência do efeito entre países com perfis econômicos amplamente variados sugere que o SES não é o principal determinante.

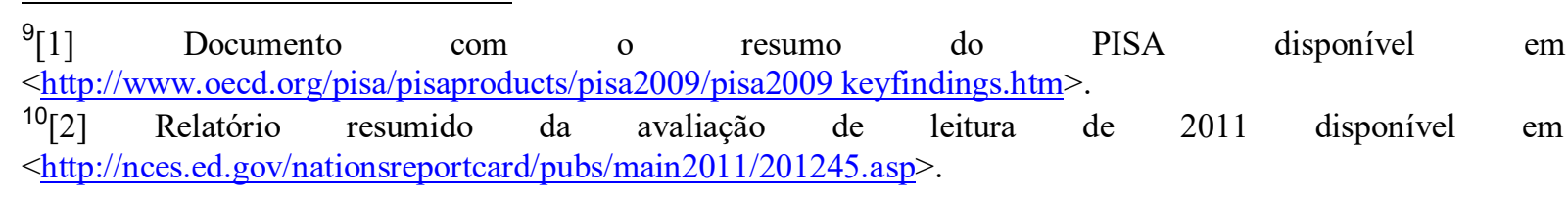


Considerando que os EUA não parece propenso a reduzir ou eliminar substancialmente a pobreza tão cedo, e o SES não é o único fator que afeta os resultados da leitura, este artigo não termina aqui. Para reafirmar a questão: Quais são as principais causas de falhas na leitura nos Estados Unidos (e talvez em outros países onde existem condições semelhantes), e tem a ciência da leitura algo a contribuir para reduzi-las significativamente, apesar do impacto considerável da pobreza? Vou considerar essa questão examinando três tipos diferentes de fatores, frequentemente apontados como relevantes para os resultados da literacia nos Estados Unidos.

\section{Culpar a língua inglesa?}

Uma possibilidade é que um certo número de pessoas esteja fadado a não aprender a ler bem por causa das propriedades intrínsecas da língua inglesa. A tarefa inicial das crianças é aprender como o código escrito se relaciona com a língua falada que elas já conhecem. $\mathrm{O}$ sistema de escrita é alfabético, e dizemos aos leitores iniciantes que as letras correspondem aos sons. Mas então ensinamos a eles o vocabulário de leitura iniciante, que inclui TER, DAR, DIZER, ALGUM, ERA, FORAM, É, MIM, UM, QUEM, ESCOLA ${ }^{11}$ e muitas outras palavras com correspondências atípicas entre a ortografia e o som. Essas inconsistências são uma propriedade muito comentada do inglês. Outros sistemas de escrita alfabética são realmente mais consistentes nesse nível de análise, muitos deles em conformidade (em alto grau, embora não perfeitamente) com o princípio de que cada símbolo no sistema de escrita (um "grafema" que consiste em uma ou mais letras) corresponde a uma única unidade (um fonema) na língua falada. Comenta-se que o inglês tem uma ortografia "opaca", enquanto italiano, alemão, russo, finlandês, coreano, servo-croata e muitos outros alfabetos são "transparentes" (KATZ; FROST, 1992). A língua inglesa escrita é obviamente um sistema viável, mas a curva de aprendizado é íngreme e uma proporção maior de indivíduos pode ficar para trás, diferentemente do aconteceria se o sistema de escrita fosse transparente.

Essa hipótese é contrariada pelo desempenho consistentemente alto em leitura de países como Canadá, Nova Zelândia, Austrália e Cingapura, onde o inglês também é a principal língua de instrução (à exceção de Quebec, devidamente observada). Embora esses resultados possam sugerir que o inglês escrito não seja o problema, talvez o desempenho fosse ainda maior nesses países (e nos Estados Unidos) caso não fosse tão peculiar. Essas descobertas internacionais são correlacionais, é claro. Precisamos de uma evidência mais direta sobre ser ou não mais fácil aprender a ler em ortografias alfabéticas transparentes, mantendo outros fatores de lado na medida do possível.

Pesquisadores de diferentes países estão abordando esta questão. Neste momento, está evidente que é mais fácil aprender a ler palavras e não-palavras em voz alta em ortografias alfabéticas transparentes em comparação com a língua inglesa (ver ARO; WIMMER, 2003, HULME; SNOWLING, 2005, e JOSHI; AARON, 2006). A vantagem da transparência ortográfica foi observada em italiano, espanhol, alemão, francês, finlandês, sérvio, turco e outras línguas. "Aprender a ler em albanês" é "uma habilidade facilmente adquirida", de acordo com Hoxhallari, van Daal e Ellis (2004), porque o alfabeto é muito transparente. As crianças conhecem o conjunto completo de correspondências ortográficas do finlandês, cuja ortografia é transparente, no momento em que a educação formal começa (aos 7 anos de idade, após um

\footnotetext{
${ }^{11}$ N.T.: as palavras HAVE, GIVE, SAID, SOME, WAS, WERE, IS, ME, ONE, WHO, SCHOOL, em inglês, apresentam irregularidades na relação grafema-fonema e por isso são usadas como exemplos pelo autor. Podemos tomar como exemplo a palavra "era" em português: a letra "e" representa dois fonemas distintos, "ê" com pronúncia fechada e "é" com pronúncia aberta. Um leitor iniciante pode ler "era" como "êra" e não associar a palavra ao verbo ser no pretérito imperfeito.
} 
ano obrigatório de pré-escola). ${ }^{12}$ Testadas em suas habilidades de ler palavras e não-palavras em voz alta, as crianças do País de Gales que aprendem a ler em galês (cujo alfabeto é transparente) superam as crianças da mesma região que aprendem a ler em inglês (HANLEY et al., 2004). Os estudos galeses permitiram comparações que excluíam muitos fatores socioeconômicos e culturais potencialmente confusos. Tais estudos sugerem, resumidamente, que a ortografia transparente é mais fácil. Share (2008) argumenta que as teorias da leitura desviaram-se por causa da dependência excessiva dos estudos realizados em inglês, um "ponto fora da curva" entre os sistemas de escrita. Talvez houvesse maior desempenho em literacia nos Estados Unidos se o sistema de escrita fosse mais parecido com o finlandês ou o albanês.

Eu acho que não. Por um detalhe, esta pesquisa comparativa sobre aquisição da leitura comete o erro de equiparar a tarefa de ler palavras e não-palavras em voz alta com "leitura" (como ARO; WIMMER, 2004; SPENCER; HANLEY, 2003; e muitos outros estudos). Às vezes, as crianças são convidadas a ler em voz alta, nas salas de aula e nos experimentos; a leitura em voz alta fornece evidências notórias sobre o conhecimento de palavras e a oportunidade de fornecer feedback explícito (por exemplo, correções de pronúncias equivocadas ). Devido à natureza do sistema de escrita, aprender a nomear palavras e nãopalavras em voz alta em inglês é um passo importante na aquisição da leitura. A tarefa também tem fornecido um domínio no qual explora-se procedimentos de aprendizagem estatística (HARM; SEIDENBERG, 1999), que são relevantes para a aquisição da linguagem, cognição visual e muito mais. O objetivo da leitura, no entanto, é a compreensão. A leitura em voz alta está muito mais fortemente relacionada à compreensão em inglês do que em ortografias transparentes (ver, por exemplo, LINDGREN; DE RENZI; RICHMAN, 1985). Nas ortografias transparentes, a leitura em voz alta pode ser realizada sem que haja compreensão do que está sendo dito, e mesmo sem conhecer a língua. Sei que isso é verdade pelo que ocorreu no meu Bar Mitzvah. O hebraico moderno pode ser escrito com ou sem vogais. Com as vogais incluídas, o sistema de escrita é transparente: as palavras têm correspondências simples e consistentes entre som-ortografia, que podem ser aprendidas rapidamente, não sendo necessária a compreensão. Felizmente, o hebraico é uma boa "língua Bar Mitzvah" (SEIDENBERG, 2011), assim como o finlandês, o albanês, o galês, o italiano e outras ortografias alfabéticas transparentes.

Não se deve, no entanto, confundir papagaiar o escrito ${ }^{13}$ com compreensão leitora. Phil Gough não confundiria. De acordo com a "visão simples da leitura" (HOOVER; GOUGH, 1990), a compreensão leitora das crianças é o produto das habilidades de decodificação (reconhecer letras, relacionando a escrita com o som) e do conhecimento da língua oral (vocabulário e gramática). Essas habilidades são dissociáveis. Se o sistema de escrita for suficientemente transparente, uma pessoa pode aprender a ler em voz alta sem que a compreensão ocorra (meu hebraico). Por outro lado, uma pessoa pode conhecer muito bem uma língua falada sem conseguir lê-la (como acontece com a maioria das crianças de 5 anos que falam inglês). Entre clínicos e pesquisadores, existe um movimento para reservar o termo "dislexia" para um comprometimento no desenvolvimento da leitura que interfira na aquisição de habilidades básicas relacionadas ao material escrito, especialmente a capacidade de relacionar a escrita com o som, independentemente da compreensão da língua oral (SNOWLING; HULME, 2011). Outras crianças adquirem habilidades adequadas de decodificação, mas compreendem mal os textos; essas crianças também são "leitores precários", mas é necessária uma categoria diagnóstica diferente, porque sua baixa compreensão em leitura é secundária às deficiências na língua oral.

\footnotetext{
12 [3] Informações sobre a educação fundamental finlandesa estão disponíveis em $<$ http://www.oecd.org/pisa/pisaproducts/46581035.pdf $>$.

${ }^{13}$ N.T.: o autor utiliza a expressão barking at print.
} 
Dado que é fácil aprender a decodificar em ortografias transparentes, isso confere uma vantagem na compreensão também? Poucos estudos examinaram atentamente a leitura em voz alta, a compreensão leitora e as habilidades da língua falada nas mesmas crianças, embora haja algumas pistas interessantes. Os estudos com crianças aprendendo a ler em galês e inglês produziram uma troca interessante: enquanto as crianças galesas tiveram um desempenho muito melhor ao ler palavras comuns e pseudopalavras simples em voz alta, as crianças inglesas tiveram uma pontuação mais alta quando testadas em compreensão. Como Hanley et al. (2004) observou, "esse resultado sugere que uma ortografia transparente não confere nenhuma vantagem no que diz respeito à compreensão da leitura. Como a compreensão é claramente o objetivo da leitura, esse resultado é potencialmente tranquilizador para os professores de inglês" (p. 1408). O porquê das crianças inglesas apresentarem melhor compreensão e pior leitura em voz alta, certamente não pode ser determinado a partir desses estudos. A comparação entre crianças aprendendo a ler em galês e em inglês não é totalmente clara porque nesse contexto sociolinguístico o inglês é a língua dominante. As crianças que aprendem galês, portanto, têm conhecimento substancial de inglês (e são bilíngues em alguma medida), enquanto as crianças que aprendem inglês têm muito menos conhecimento de galês e são essencialmente monolíngues. O que fica claro é que a capacidade de ler em voz alta pode revelar pouco sobre a compreensão leitora da criança.

Durgunoglu (2006) chegou a uma conclusão semelhante a partir de extensos estudos sobre leitura em turco. O turco possui uma ortografia transparente e uma morfologia complexa, aglutinadora e altamente produtiva. Resumindo, ela observou que "a consciência fonológica e a decodificação se desenvolvem rapidamente em jovens e adultos leitores de turco, devido à ortografia transparente e às características especiais da fonologia e da morfologia. No entanto, a compreensão da leitura ainda é um problema" (2006, p. 226). Em seus experimentos, a compreensão das crianças foi substancialmente inferior à capacidade de pronunciar palavras em voz alta, o que ela atribui às propriedades da linguagem falada, especificamente o sistema morfológico complexo, que leva muitos anos a ser aprendido pelos falantes nativos.

Enquanto a compreensão se desenvolve mais rapidamente do que a produção ao longo do processo de aprender uma primeira língua, as ortografias transparentes criam o efeito oposto: a produção - ler em voz alta - pode avançar mais rapidamente do que a compreensão.

Mesmo em inglês, a acurácia da leitura em voz alta e a compreensão da leitura frequentemente se dissociam. Leitores hábeis são capazes de ler e compreender muitas palavras que pronunciam incorretamente. Aqui estão alguns exemplos que coletei de estudantes e colegas - palavras que eles não sabiam pronunciar ou pronunciavam incorretamente sistematicamente por muitos anos ${ }^{14}$ :

$\begin{array}{ll}\text { Egregious } & \text { Coitus } \\ \text { Piquant } & \text { Clitoris } \\ \text { Suave } & \text { Epitome } \\ \text { Rapport } & \text { Segue } \\ \text { Quay } & \text { Facade } \\ \text { Hegemony } & \text { Ennui } \\ \text { Automata } & \text { Sleight } \\ \text { Chaos } & \text { Uranus }\end{array}$

Tudo verdade. Um estudante de pós-graduação que passou parte de sua juventude imerso no jogo de computador Chaos: The Battle of Wizards levou muito tempo para perceber que estava conectado à forma falada /kei-as/. As duas pronúncias de URANUS parecem estar

\footnotetext{
${ }^{14}$ N.T.: Na língua portuguesa é comum que palavras como rubrica, indigno, filantropo, idiossincrasia, sintaxe, tranquilo, procrastinar, regozijar, devido à baixa frequência de uso na linguagem falada, sejam pronunciadas de forma distinta da padrão por alguém que se depara com elas pela primeira vez.
} 
em livre variação nos Estados Unidos. As pessoas podem ser mais adeptas a praticar o "coito" do que a pronunciá-lo. Um exemplo pessoal: o modelo de Seidenberg e McClelland (1989) aprendeu a pronunciar QUAY ${ }^{15}$ como $/ \mathrm{kwei} /$ porque o léxico de treinamento foi criado à mão e foi assim que pensei que fosse pronunciado (isso foi corrigido em modelos posteriores). Como um garoto que cresceu longe do mar, no sul de Chicago, eu conhecia a palavra somente na forma escrita. Esses casos mostram que uma pessoa pode conhecer o significado de uma palavra escrita, mas não possuir um conhecimento seguro da pronúncia. É comum que alguém pronuncie uma palavra de forma incorreta no caso de nunca tê-la usado na linguagem falada. Se essas palavras fizessem parte de um experimento de leitura em voz alta, até leitores de inglês adultos e altamente qualificados teriam um desempenho pior do que os indivíduos galeses ou turcos.

Nation e Cocksey (2009) descobriram que crianças de 7 anos de idade que falam inglês geralmente sabem o significado das palavras que leem incorretamente em voz alta. A familiaridade com a palavra falada (conforme indexada pelo desempenho em [tarefas] de decisão lexical auditiva) estava relacionada à acurácia ao lê-la em voz alta, especialmente para palavras com correspondências grafofonológicas irregulares. Entre os sujeitos, 521 palavras foram lidas em voz alta incorretamente; a definição correta foi fornecida para 328 delas $(63 \%)$. É claro que o fato de a capacidade de compreender e a capacidade de pronunciar palavras podem se dissociar deveria ter sido óbvio pela mera existência de surdos com deficiência auditiva grave que não recebem treinamento oral, não conhecem a pronúncia das palavras, mas são bons leitores. (O fato de ser difícil tornar-se um leitor hábil nessas condições é uma questão importante, mas separada; GOLDIN-MEADOW; MAYBERRY, 2001).

Em suma, a leitura em voz alta não é um bom índice de compreensão leitora ou uma base para avaliar a "facilidade de aprender a ler" diferentes sistemas de escrita. Portanto, devemos ser céticos em relação às alegações de que é fácil aprender a ler em ortografias transparentes e à crença corolária de que o inglês é particularmente difícil. Nos últimos 20 anos, pesquisadores de vários países reconheceram a devida importância de obter dados sobre leitura em outras línguas que não o inglês, mas tentaram corrigir esse desequilíbrio replicando estudos realizados em inglês através da leitura em voz alta, uma tarefa que está mais estreitamente relacionada à compreensão nessa língua justamente por causa das idiossincrasias ortográficas que estavam tentando superar.

\section{A relação entre sistemas de escrita e línguas faladas}

A hipótese da opacidade ortográfica é um exemplo de uma ideia interessante que chamou a atenção para uma questão importante (as diferenças em como os sistemas de escrita representam a fonologia e seu potencial impacto na leitura) e estimulou uma enorme quantidade de pesquisas, mas acabou por estar incorreta. A hipótese se concentrou estritamente na computação da fonologia a partir da escrita. Considerando a dependência da leitura na linguagem oral, parecia lógico que os sistemas de escrita para os quais era mais fácil computar a fonologia, os transparentes, também seriam mais fáceis de compreender, mantidos idênticos aos outros fatores. Essa previsão não se mostrou correta porque os outros fatores são evidentemente desiguais. Observando línguas e sistemas de escrita, pode-se perceber que as propriedades dos sistemas de escrita estão relacionadas às propriedades das línguas que eles representam, em particular a complexidade da morfologia flexional da língua. A morfologia flexional é um componente especialmente importante da linguagem porque é um sistema de

${ }^{15}$ N.T.: em português, cais [do porto]. O exemplo funciona também em português porque a palavra pode ser pronunciada como monossílabo (como de fato é) ou como dissílabo: ca-is (sem acento, como oxítona - nesse caso, por uma pessoa que não conhece a pronúncia padrão). 
interface que transmite informações sobre as palavras e as estruturas sintáticas das quais elas participam, e uma fonte importante de variação tipológica. Línguas como o galês e o turco têm sistemas de escrita transparentes, mas são morfologicamente complexas, marcando propriedades como caso, número e gênero. O inglês e as línguas siníticas (mandarim, tailandês, cantonês e outras) exibem o padrão oposto: os sistemas de escrita são opacos, mas seus sistemas flexionais são simples. Observando a língua inglesa, Gough concluiu que a compreensão precoce da leitura é um produto do conhecimento da escrita e do conhecimento da língua falada. Com uma perspectiva multilíngue, fica claro que os dois componentes não são independentes. O que deve ser aprendido sobre a escrita depende das propriedades do sistema de escrita, que mantêm uma relação não arbitrária com a tipologia da língua falada.

Busquei unificar essas amplas tendências multilíngues sob o conceito de "equilíbrio grafolinguístico" (SEIDENBERG, 2011). Os sistemas de escrita que sobreviveram sustentam a compreensão igualmente bem. A capacidade de um sistema de escrita para apoiar a compreensão pode ser pensada como uma constante que é mantida através de trocas entre a complexidade ortográfica (por exemplo, "opacidade", número e complexidade de símbolos) e a complexidade da linguagem falada (particularmente morfossintática). Para línguas como o galês ou o turco, as correspondências entre ortografia e som são facilmente aprendidas, ao contrário da morfologia. Essas condições permitem que as crianças leiam com precisão frases em voz alta que não seriam capazes de produzir ou compreender completamente, considerando seu conhecimento ainda em desenvolvimento da língua falada. O inglês escrito é opaco, mas o sistema flexional é trivial e de pouco impedimento à compreensão. Sob essas condições, as crianças produzem e compreendem facilmente frases que não conseguem ler com precisão em voz alta.

Uma ortografia opaca seria altamente disfuncional, possivelmente inapreensível, em línguas com morfossintaxe complexa. Para ilustrar, considere o servo-croata. Os estudos clássicos focaram em suas correspondências grafofonológicas altamente consistentes, bem diferentes daquelas em inglês (KATZ; FROST, 1992). Meus colegas e eu estávamos mais interessados em seu sistema flexional (MIRKOVIC' et al., 2004, 2011), que também é muito diferente do inglês. O sistema é inquestionavelmente complexo. Tanto os substantivos quanto os verbos são flexionados e há inflexões para número, gênero, caso e tempo verbal. As inflexões não são independentes: o número nos substantivos, por exemplo, depende de caso e gênero.

TABLE 1

A Fragment of Inflectional Morphology in Serbian

\begin{tabular}{lll}
\hline Word & Case and number & \multicolumn{1}{c}{ Inflection } \\
\hline SAVETNIK & Nominative singular & Zero inflectted \\
SAVETNICI & Nominative plural & $-\mathrm{I}$ \\
SAVETNIKA & Genitive singular & $-\mathrm{A}$ \\
SAVETNIČE & Vocative singular & $-\mathrm{E}$ \\
SAVETNIKE & Accusative plural & $-\mathrm{E}$ \\
\hline
\end{tabular}

Note: All forms are masculine gender. $\mathrm{K}=/ \mathrm{k} /$ as in Kevin, $\breve{\mathrm{C}}=/ \mathrm{t} \mathrm{f} /$ as in "church," $\mathrm{C}=/ \mathrm{ts}$ / as in "pizza."

As flexões, além disso, não são unidades individuais em sequência ${ }^{16}$ : o sistema é de fusão, de modo que um único sufixo codifica várias flexões. Assim, há uma irregularidade a

\footnotetext{
${ }^{16}$ N.T.: a expressão usada pelo autor é beads on a string, que pode ser traduzida literalmente como "contas em um cordão", mas seu uso metafórico é aplicado a vários domínios.
} 
mais: a realização de uma flexão depende das propriedades fonológicas da raiz à qual está ligada (Tabela 1). A forma base para SAVETNIK (masculino, "orientador") é zero-flexionado. A consoante final $\mathrm{K}[/ \mathrm{k} / \mathrm{]}$ não é retida em todo o paradigma flexional, mudando para $\mathrm{C}[/ \mathrm{ts} / \mathrm{e}$ ${ }^{\smile} \mathrm{C}[/ \mathrm{tS} /]$. A flexão -E é usada tanto para o singular vocativo quanto para o plural acusativo; no primeiro, é precedido por ${ }^{`} \mathrm{C}$, no segundo, por K. Fica claro mesmo a partir desse fragmento da língua que há muito a aprender.

Agora, imagine tentar ler essa língua em um sistema de escrita mais parecido com o inglês, com letras que representam várias vogais (por exemplo, o som inicial de OVO e $\mathrm{OVOS}^{17}$ ). Em seguida, pense em algumas consoantes com várias pronúncias, como $\mathrm{C}$ (em CAPA e CENTAVO), G (GOIABA, GIN) e X (XÍCARA, TÁXI, EXCESSO $)^{18}$. A complexidade do sistema flexional já é alta. Adicionar ambiguidade às pronúncias das letras escritas aumentaria o grau de complexidade enormemente. A forma adequada de uma flexão depende da pronúncia da consoante anterior, já a pronúncia da letra que representa essa consoante às vezes também depende do contexto (como nas letras ambíguas do inglês). Haveria outras desvantagens se o domínio de um sistema morfológico complexo exigir instruções formais que envolvam a leitura.

Seriam necessárias análises quantitativas ou modelos de simulação para determinar os efeitos da indeterminação ortográfica adicional e estabelecer quando o sistema se tornaria intratável para os aprendizes humanos. O fato histórico de que línguas com sistemas morfológicos complexos têm ortografias pouco opacas é, entretanto, sugestivo de pressões para manter esse equilíbrio. De fato, muitas vezes o alinhamento da língua e do sistema de escrita foi alcançado com intervenção ativa, como no alfabeto armênio no século V, Hangul na Coreia do século XV e servo-croata no século XIX (ver DANIELS; BRIGHT, 1996).

Em suma, não existe almoço ortográfico grátis. A criança começa a ler mais rapidamente se as associações entre as unidades da língua escrita e da língua oral forem simples e consistentes. No entanto, aprender a ler em voz alta em sistemas de escrita transparentes é um pouco como aprender a tocar violino no método Suzuki. Ambos permitem que rapidamente a criança obtenha desempenho com relativamente pouca instrução. O desempenho de uma criança de quatro anos nas "Twinkle Variations" ${ }^{19}$ pode muito bem ser o equivalente musical a papagaiar o escrito. Ser capaz de pronunciar palavras em voz alta é uma habilidade útil se sua tarefa é aprender um sistema morfológico complexo e quase-regular durante um período de muitos anos que se estende ao longo da escolarização formal. Porém, existem poucas evidências de que o conhecimento precoce das correspondências grafofonológicas confira uma vantagem para a compreensão ou que as irregularidades no inglês escrito apresentem um ônus especial. ${ }^{20}$

\footnotetext{
17 N.T.: os exemplos dados pelo autor são: várias vogais em DOSE, LOSE, POSE; consoantes com várias pronúncias como C (CAP e CENT), G (GOAT, GIN) e Y (YOUNG, EDGY).

${ }^{18}$ N.T.: Podemos comparar as flexões que ocorrem em língua portuguesa como, por exemplo, no gênero em que a vogal "a" é adicionada à palavra professor (masculino), sendo professora (feminino). Em inglês a palavra "teacher" é usada tanto para o feminino quanto para o masculino, no entanto, trata-se de uma palavra de pouca transparência na pronúncia.

${ }^{19}$ N.T. O autor se refere à música infantil, tocada ao violino, que em português é traduzida como "Brilha, brilha estrelinha".

20 [4] O hebraico é o sistema de escrita mais atípico? Aparentemente contrário à minha análise, é morfologicamente complexo, mas também ortograficamente opaco na forma padrão e sem pontuação. Observe, no entanto, que as crianças aprendem a ler usando a forma transparente na qual as vogais são indicadas por diacríticos (niqqud). Aprender a ler usando a forma não pontuada seria muito mais difícil (embora talvez tenha sido alcançado pela antiga elite dos escribas antes do desenvolvimento do sistema diacrítico).
} 
Volume 15 - Número 2 - ago/dez de 2020

\section{E quanto à forma como a leitura é ensinada?}

Os educadores americanos nunca conseguiram estabelecer o melhor modo de ensinar as crianças a ler. A questão tem sido debatida desde que Horace Mann foi chefe do Conselho de Educação de Massachusetts na década de 1840. Mann descreveu as letras como "esqueléticas, sem sangue e fantasmagóricas" e incentivou as crianças a lerem palavras inteiras de uma vez uma lição que "será como uma excursão aos campos elísios" em comparação com outras práticas. O tom de Mann - afirmação autoritária aliada ao desprezo por outras visões caracteriza boa parte dos 150 anos subsequentes de debate. ${ }^{21}$

Que proporção do problema da literacia nos Estados Unidos se deve à maneira como a leitura tem sido ensinada? Todos conhecemos as "guerras da leitura" dos últimos 30 anos - o debate sobre os métodos "fônico" e "global". Os anos 2000 viram o surgimento de uma abordagem chamada "Alfabetização equilibrada", que incorporava os melhores aspectos de ambas as abordagens. A "alfabetização equilibrada" é uma solução Tratado de Versalhes, que permitiu aos educadores declararem o fim das "guerras" cada vez mais problemáticas sem ter abordado seriamente as causas subjacentes da luta. As questões são complexas, controversas e contínuas. Examino aqui, brevemente, algumas considerações básicas na perspectiva de um cientista que estuda como a leitura funciona, sugerindo que o modo como a leitura é ensinada é de fato uma parte significativa do problema da literacia nos Estados Unidos e em outros países. Destaco três pontos principais: (a) A ciência da leitura contemporânea teve pouco impacto na prática educacional, principalmente devido a um problema de duas culturas separadas: ciência e educação; (b) Essa desconexão tem sido prejudicial. As práticas atuais se apóiam em suposições desatualizadas sobre leitura e seu desenvolvimento, que tornam o aprendizado da leitura mais difícil do que deveria ser, uma maneira de deixar muitas crianças para trás; (c) Conectar a ciência à prática educacional seria benéfico, mas é algo extremamente difícil de alcançar. $\mathrm{O}$ ambiente atual limita a quantidade de trabalho colaborativo em todas as interfaces translacionais importantes. Nos Estados Unidos, os interesses conflitantes e muitas vezes fortemente arraigados de várias partes interessadas - educadores, políticos, cientistas, contribuintes, organizações trabalhistas, grupos de pais - dificultam a realização de mudanças significativas na estrutura institucional existente da educação pública.

Meus comentários sobre a cultura da educação (com os quais me refiro às crenças e atitudes sobre como as crianças aprendem e as funções da escola, particularmente no que diz respeito à leitura) podem parecer duros para os leitores que não estão próximos a esses problemas. Muitas pessoas presumem naturalmente que, embora pesquisadores e professores possam ter visões diferentes, ambos têm muito a contribuir e o caminho para que haja mais progresso é através da cooperação. Todo pesquisador está ciente da importância do trabalho interdisciplinar e dos desafios envolvidos na comunicação entre as disciplinas. Sabemos também que a criação bem-sucedida de pontes interdisciplinares pode gerar transformações,

\footnotetext{
${ }^{21}$ [5] A citação de Mann (que encontrei pela primeira vez em Adams, 1990) é de um relatório de 1844 que ele preparou como secretário (chefe) do Conselho de Educação de Massachusetts, no qual ele era altamente crítico às escolas locais, comparando-as desfavoravelmente às salas de aula que ele tinha observado na Prússia e na Escócia (obscurece nossa atual inveja das práticas educacionais da Finlândia e de Xangai!). Muito ofendidos, os professores das escolas públicas de Boston publicaram uma réplica, na qual comentaram que "nossa discordância das visões [de Mann] decorre de uma convicção honesta de que, se adotadas, retardariam o progresso da aprendizagem do som". Mann estava defendendo o que mais tarde ficou conhecido como o método de palavras inteiras (wholeword) ou "olhe e diga", que envolve a memorização de palavras como padrões, sem levar em consideração as funções das letras componentes. Os educadores de Boston eram a favor de um método de ensino "fonético". Sua oposição ao "novo método" de Mann foi minuciosa e incisiva, mas não resolveu nada. Os argumentos de ambos os lados serão facilmente reconhecíveis por qualquer pessoa familiarizada com as "Guerras da Leitura" dos últimos 30 anos. Todos os documentos (os lados retrocedem e avançam algumas vezes) estão disponíveis como e-books no Google Play e são altamente recomendados.
} 
algumas vezes levando ao surgimento de novos campos que são muito mais do que a soma das partes disciplinares. Essa transformação é necessária na educação e espero que ela possa ser alcançada. A questão é como fazer isso. Pode ser complicado, para quem não está familiarizado com esse cenário, estimar quão difíceis são os desafios. Como alguém que esteve imerso nessas questões por muitos anos, lutei para encontrar maneiras de criar um impacto positivo, e isso se reflete no material a seguir (ver também Seidenberg, 2012).

Talvez você acredite, assim como eu, que a abordagem colegial e politicamente perspicaz implica em presumir que indivíduos bem-intencionados são capazes de transcender suas diferenças a serviço de um objetivo em comum. As barreiras disciplinares só existem enquanto permitimos que elas existam. Todos nós podemos realizar trabalhos melhores comunicando o que fazemos e o que aprendemos. As pontes são construídas sobre uma base de respeito pelos indivíduos e pelos diversos pontos de vista. Todos fazem o melhor que podem; nenhum dos lados sabe tudo. Apoio totalmente a construção de pontes criativas e tenho me envolvido com isso, porém me questiono se boas intenções e maior esforço podem ser mais eficazes daqui para frente do foram no passado. Esses impulsos positivos e sinceros poderiam ter maior chance de sucesso se houvesse mais compreensão das profundas diferenças entre as culturas da ciência e da educação, que se manifestam em suas abordagens discordantes da leitura (ver também SEIDENBERG, 2013).

É importante observar que há uma variedade de bons trabalhos científicos relevantes sendo conduzidos no âmbito da educação, geralmente em departamentos como de psicologia educacional; no entanto, estão isolados de programas focados na formação profissional dos professores e no desenvolvimento de currículos e práticas de ensino. Meus apontamentos sobre a cultura da educação se concentram no âmbito dos treinamentos e práticas. Devo também enfatizar que minhas preocupações não estão relacionadas aos professores, mas ao que se ensina aos professores (sobre desenvolvimento infantil em geral e sobre leitura em particular) e como os currículos e práticas instrucionais são criados e avaliados. Não estou desafiando a integridade de ninguém, tampouco o compromisso, motivação, esforço, sinceridade ou inteligência. Estou desafiando algumas crenças profundamente arraigadas que orientam políticas e práticas educacionais há muitos anos. A expectativa é de que isso seja desconcertante para muitas pessoas, mas que também seja algo reconhecido como relevante para seus compromissos mais profundos em ajudar os alunos a aprender.

Por fim, reconheço que meu tratamento para tais problemas está incompleto, considerando as limitações de espaço deste artigo. Caracterizo a seguir, principalmente a situação atual, e não como ela surgiu. A resistência à ciência da leitura de um passado recente também precisa ser considerada em um contexto histórico, que inclui tentativas anteriores de fundamentar as práticas educacionais na ciência do momento. Além disso, é importante que analisemos o contexto à luz de outros desafios ao controle tradicional dos educadores sobre políticas e práticas educacionais (incluindo intervenção federal via legislação como No Child Left Behind ${ }^{22}$, e novas filantropias educacionais poderosas; RAVITCH, 2011). Apresento esse contexto mais amplo em Seidenberg (2013).

\section{As duas culturas da ciência e da educação}

Aprender a ler é uma questão educacional, historicamente da competência dos professores, especificamente dos cursos de Pedagogia. A história da educação nos Estados

\footnotetext{
22 Programa No Child Left Behind (nenhuma criança deixada para trás). Lei assinada pelo ex-presidente norte americano George W. Bush no ano de 2002 com o objetivo de recuperação do nível de desempenho educacional do país e a eliminação da diferença nesse quesito ("achievement gap") que desfavorece os negros e os hispânicos em relação aos brancos.
} 
Unidos foi extensivamente documentada, principalmente sob a perspectiva dos próprios educadores (RAVITCH, 2000; CREMIN, 1988). Com certo distanciamento, percebe-se que a ciência e a educação ocupam diferentes territórios no mundo intelectual (literalmente em muitos campus universitários). O resultado é que pessoas que estudam o mesmo assunto - como as crianças aprendem a ler, por exemplo - podem, no entanto, ter pouco contato. As culturas da educação e da ciência são radicalmente diferentes: elas têm objetivos e valores diferentes, maneiras de formar novos profissionais e critérios para avaliar o progresso. As duas culturas também comunicam suas pesquisas em conferências separadas patrocinadas por organizações profissionais paralelas voltadas a diferentes públicos e publicam seus trabalhos em periódicos diferentes. Existem editores que têm como alvo um público ou outro. Essas diferenças interculturais, bem como muitas outras, dificultam uma união.

Psicólogos estudam a leitura desde o século 19 e os educadores têm tido uma abordagem de evitar o conflito desde então. A educação como disciplina abraçou alguns teóricos com raízes na psicologia moderna - Dewey, Vygotsky, Piaget e Bruner entre outros - cujo trabalho é subjacente à abordagem "construtivista" profundamente arraigada na educação (TOBIAS; DUFFY, 2009). Existe um profundo ceticismo quanto à relevância de estudos empíricos que utilizam as ferramentas da moderna psicologia cognitiva experimental e da psicologia do desenvolvimento, seja em laboratórios ou nas salas de aula (por exemplo, COLES, 2000); entretanto, coexiste com uma prontidão para se apropriar de resultados que estejam em consonância com as crenças e práticas existentes. O papel especial de ciência - descobrir, da melhor maneira possível, o que é verdade, deixando as implicações se inclinarem para onde for possível - é subvertido quando se atende seletivamente às descobertas consideradas agradáveis: transforma as pesquisas em outra forma de anedota. Os educadores também usam nossa pesquisa como fonte de novas descobertas que alimentam a demanda constante por inovação educacional. Frequentemente, isso significa uma empolgação muito rápida com descobertas que apesar de interessantes e novas não estão solidamente estabelecidas ou compreendidas.

As atitudes conflitantes entre ciência e educação estão no centro das controvérsias sobre o ensino da leitura. O que chamarei de Síntese Moderna sobre aprender a ler, habilidades de leitura, e a relação entre leitura e linguagem emergiu de um trabalho realizado desde 1970, começando com Gibson e Levin (1978), Liberman et al. (1977), Gough (por ex., GOUGH; HILLINGER, 1980; HOOVER; GOUGH, 1990), Stanovich (1980) e outros. Quase toda essa pesquisa foi conduzida por pesquisadores trabalhando fora dos departamentos tradicionais da educação. As descobertas empíricas subjacentes à Síntese Moderna foram resumidas em várias publicações encomendadas por diferentes agências (ADAMS, 1990; SNOW; BURNS; GRIFFIN, 1998; PAINEL NACIONAL DE LEITURA, 2000²3; SNOW, 2002; LONIGAN; SHANAHAN, 2009). Essa pesquisa trouxe à luz pressupostos básicos acerca de como a leitura é ensinada e o que se ensina aos professores sobre leitura e desenvolvimento - sobretudo a ideia de que a maneira como as crianças adquirem uma primeira linguagem falada fornece um bom modelo para aprender a ler - e, no entanto, tem tido pouco impacto subsequente sobre elas. Os conflitos entre abordagens científicas e educacionais da leitura continuam, centrados em três questões.

1. Decidir o que é verdade. Uma das principais diferenças interculturais diz respeito às atitudes sobre evidência. Existe um movimento para incentivar práticas baseadas em evidências na educação que é análogo às práticas da medicina e da psicologia clínica (ver http://ies.ed.gov/ncee/wwc). O esforço cai por terra, entretanto, se as partes interessadas não concordarem com o que conta como evidência ou quem deve decidir sobre isso. Muitos educadores desprezam as tentativas de examinar a leitura por uma perspectiva científica, que é vista como estéril e redutora, intrinsecamente incapaz de capturar o indescritível caráter do

\footnotetext{
${ }^{23}$ NRP é a sigla para National Reading Panel, Painel Nacional da Leitura.
} 
momento da aprendizagem ou a química de uma sala de aula bem-sucedida (COLES, 2000). A educação como disciplina valorizou muito mais a observação e a experiência adquirida em sala de aula. Essa divisão ficou evidente nas reações ao relatório NRP (2000). O painel revisou a literatura científica relevante ao aprendizado da leitura, tendo estabelecido critérios a priori explícitos para que tipos de estudos seriam considerados. Esses critérios excluíam estudos que os educadores valorizam: principalmente estudos observacionais e quase etnográficos de escolas, professores, salas de aula e crianças que não estavam de acordo com os princípios básicos dos projetos experimentais de pesquisa ou análise de dados (por ex., BARTON; HAMILTON, 1998; RASINSKI; YILDIRIM; NAGELDINGER, 2011). O relatório foi, portanto, de pouco interesse para muitos educadores, exceto como evidência de um viés científico tendencioso em desacordo com os valores centrais estabelecidos no âmbito educacional (KRASHEN, 2001) ${ }^{24}$.

Na perspectiva dos estudos modernos da cognição, a confiança dos educadores nas suas próprias observações e experiências em sala de aula é desconcertante. Se os professores realmente pudessem compreender como a leitura funciona e como as crianças aprendem apenas por observação e experiência, não haveria um problema sequer de literacia ou debates sobre as melhores práticas. Mas o que podemos aprender sobre leitura dessa forma é limitado. A maior parte do que fazemos quando lemos é subconsciente: temos consciência do resultado - se entendemos um texto ou não, se encontramos as informações que buscamos. Nem professores nem pesquisadores conseguem observar diretamente os processos mentais e neurais das crianças; o que pode ser intuído sobre eles com base na experiência da sala de aula é limitado, e as intuições são geralmente conflitantes. Introspecção e observação pessoal sistemática foram as principais metodologias utilizadas pelos fundadores da psicologia moderna (BORING, 1953), mas a descoberta de suas limitações levou à adoção de métodos menos dependentes do observador. As limitações são ainda maiores do que os primeiros psicólogos podiam saber. $\mathrm{O}$ que as pessoas observam depende do que elas acreditam (ver COX; MYERS; SINHA, 2004, para uma ilustração impressionante). Inferências baseadas em observação estão sujeitas a preconceitos arraigados que exigiram uma pesquisa em nível de Prêmio Nobel para serem descobertas (KAHNEMAN, 2011). As limitações da observação pessoal e da experiência estão entre as razões pelas quais conduzimos esse outro tipo de pesquisa, a científica: entender os componentes da leitura que estariam escondidos da visão e fazê-lo de maneira objetiva, independentemente verificável. Uma psicologia popular sobre como lemos com base na intuição e na observação não se torna mais confiável quando elevada a princípio educacional, mas essa é a história moderna da teoria educacional da leitura.

2. A abordagem sociocultural. A Síntese Moderna se desenvolveu a partir de pesquisas que examinaram a leitura no contexto mais amplo de pesquisas sobre a linguagem e a cognição humana e suas bases neurais e computacionais. Na educação, uma abordagem muito mais influente enfatizou os aspectos socioculturais da literacia, particularmente o status da leitura em diferentes subgrupos culturais, linguísticos e socioeconômicos (por ex., GEE, 1997; AU, 1998;

24 [6] Ver Allington e Woodside-Jiron (1999), que acreditam que muitos dos resultados da pesquisa que contradizem suas próprias visões são fruto de pesquisas financiadas por Reid Lyon, um funcionário do NICHD, como parte de uma agenda política anti-educação. O documento de base para esse movimento político, segundo os autores, é Grossen (1997), uma revisão obscura de 22 páginas sobre 30 anos de pesquisa em leitura financiada pelo NICHD. A paranóia de Allington and Woodside-Jiron é tão intensamente focada no NICHD que eles ignoram uma gama de descobertas semelhantes advindas de pesquisas conduzidas em vários outros países. As mesmas conclusões sobre a aprendizagem da leitura se encontram tanto em relatórios americanos tais como o NRP (2000) quanto no relatório Britânico Rose (ROSE, 2000). Seria mais fácil descartar a campanha de Allington contra a ciência da leitura (ver também ALLINGTON, 2002) se ele não fosse uma liderança na educação para a leitura, expresidente da International Reading Association (Associação Internacional da Leitura), ex-presidente da National Reading Conference (Conferência Nacional de Leitura) e um membro da "Reading Hall of Fame" (http://www.readinghalloffame.org). 
Volume 15 - Número 2 - ago/dez de 2020

SCRIBNER; COLE, 1981; MOJE; LUKE, 2009). A abordagem enfatiza atitudes em relação à leitura dentro desses grupos; os variados propósitos pelos quais as pessoas leem em diferentes contextos definidos por situação, cultura, idioma ou SES; a relevância de diferentes atividades relacionadas à leitura para os alunos nesses contextos; e como os fatores socioculturais afetam a motivação de uma criança para aprender a ler e quais práticas de sala de aula serão bem sucedidas.

Muito do que é afirmado na abordagem sociocultural parece bastante verdadeiro em um nível informal. A leitura não é uma tarefa unitária - o modo como lemos depende do que estamos lendo e do objetivo da leitura. Ao desenvolver um currículo, seria sensato levar em consideração o contexto cultural e socioeconômico, incluindo diferentes atitudes em relação à leitura e diferenças nas experiências e oportunidades fora da sala de aula que podem afetar muito o progresso das crianças. Esses fatores provavelmente terão forte impacto sob a motivação da criança para ler, um fator significativo amplamente ignorado pelos pesquisadores da leitura.

A pesquisa sociocultural aponta questões importantes; elas estão profundamente relacionadas às "diferenças de desempenho", que serão discutidas na próxima seção. O problema é que o paradigma sociocultural é visto como uma alternativa para estudos sobre os tipos de conhecimento e mecanismos de processamento que subjazem a leitura e como eles são adquiridos, ao invés de abordar questões complementares. A tensão entre essas abordagens forneceu o subtexto para as "guerras da leitura". O centro do conflito foi um debate sobre a validade do que foi chamado de abordagens de "habilidades" versus "literacia", que, surpreendentemente, foram vistas como alternativas concorrentes ${ }^{25}$. Os cientistas eram vistos como focados em "habilidades" (por ex., aprender a ler palavras e frases com precisão e fluência; desenvolvimento de vocabulário), enquanto os educadores enfatizavam o desenvolvimento do letramento (a apreciação pela criança dos vários tipos e usos da linguagem escrita, por indivíduos com diversas experiências, valores e tradições culturais). O tempo em sala de aula é um jogo de soma-zero ${ }^{26}$ e, portanto, as escolhas entre habilidades e letramento tinham que ser feitas. Além disso, acreditava-se que o ensino de habilidades básicas para leitores iniciantes era contraproducente porque sufoca a curiosidade natural das crianças sobre a leitura e sua motivação para aprender. Apesar de necessária, essa história de habilidades básicas também seria perigosa quando aplicada em dose ampla, portanto a criança deveria ser exposta a ela o mínimo possível. O objetivo tradicional de ensinar as crianças a ler tem sido substituído por coaching: incentivando a valorização e o engajamento em "múltiplos letramentos". A teoria educacional tornou-se "meta" em relação à leitura: há pouca informação sobre como a leitura funciona (ou seja, suas bases neurocognitivas) e muito sobre como a leitura é usada (várias "práticas de letramento") e por quem (vários grupos culturais/étnicos/linguísticos).

Esse conflito - que exponho sem exagero algum - decorre de uma falha em assumir uma perspectiva genuína de desenvolvimento. $\mathrm{O}$ ato de ler e compreender textos envolve a coordenação de capacidades cognitivas, linguísticas, perceptuais, motoras, mnemônicas e de aprendizagem. Compreender essas capacidades, como elas se desenvolvem e como são acionadas para apoiar a leitura é obviamente relevante para ajudar as crianças a se tornarem

\footnotetext{
25 [7] No cenário atual, todos têm uma abordagem "equilibrada" para a instrução de leitura, reconhecendo a importância das habilidades e da literacia. Tendo visto e compreendido o que está escrito na parede, as organizações saíram em defesa das abordagens Globais de "literacia", criando diretrizes para a instrução de "alfabetização equilibrada" (ver, COWEN, 2003, para um exemplo e MOATS, 2007, por uma crítica a esses esforços).

${ }^{26}$ N.T. zero-sum.game. Na Teoria dos Jogos, a soma zero ocorre quando o ganho obtido por um participante é equivalente à perda sofrida pelo outro participante, de forma que o resultado final é sempre o mesmo. Assim, cada participante maximiza o seu resultado às custas do outro.
} 
Volume 15 - Número 2 - ago/dez de 2020

leitores bem sucedidos. O que é importante ensinar (ou "facilitar") depende de onde a criança se encontra na sua trajetória de desenvolvimento. A capacidade de ler e compreender palavras e seus componentes é uma habilidade básica e fundamental. Ajudar a criança a alcançar essa habilidade, sem criar desinteresse pela leitura, é o desafio educacional. A aquisição dessa base permite que a criança se beneficie de outras atividades que promovem novos avanços: ampla prática de leitura de textos variados, com verificação atenta da compreensão; ler textos para diferentes fins; e ganhar conhecimento fundamentalmente relevante em relação àquilo que está sendo lido. Fatores socioeconômicos e culturais são altamente relevantes para a capacidade da criança de se beneficiar da escolaridade, mas elas não mudam a natureza do processo de leitura ou os tipos de conhecimentos e habilidades que precisam ser adquiridos.

3. Literacia cientifica. A lacuna entre as culturas garante que as pessoas provenientes da área da educação tenham poucas oportunidades de entender como as pesquisas são conduzidas em disciplinas como cognição, desenvolvimento e neurociência. Os cursos de pedagogia inserem os futuros professores em uma ideologia sobre crianças, aprendizado e leitura. Esses futuros professores não são expostos a outras pesquisas relevantes para o seu trabalho, o que é especialmente prejudicial dadas as grandes dificuldades encontradas neste campo de atuação profissional. Os educadores não estão preparados para se envolver nessa ciência de maneira séria porque não possuem as ferramentas para entender o que é estudado, como é estudado, o que é descoberto, o que isso significa e sua relação com outros tipos de pesquisa. Isso também deixa os educadores vulneráveis a afirmações intuitivamente atraentes, mas não-comprovadas, exageradas ou desacreditadas. Os professores abraçam a importância das "habilidades de pensamento crítico" e "conhecimento prévio" na leitura e na aprendizagem, e é irônico quando estão ausentes de discussões sobre pesquisas em leitura e aprendizagem. Penso que essa profunda ambivalência sobre a relevância da ciência para a missão educacional explica aspectos aparentemente contraditórios da cultura educacional, como a escolha seletiva das descobertas científicas e, ao mesmo tempo, a redução da relevância da pesquisa básica (por ex., DUKE; MARTIN, 2011). Também acho que explica por que o único mais influente teórico educacional da América é Lev Vygotsky, que viveu na União Soviética, escreveu em russo, morreu em 1934, e nunca viu uma sala de aula americana ou uma televisão, computador, calculadora, videogame ou smartphone, e ao mesmo tempo os educadores também estão buscando as últimas descobertas da neurociência para obter ajuda (por ex., WILLIS, 2007). É difícil saber o que Vygotsky, que fundou a perspectiva sociocultural para a educação como uma alternativa às abordagens baseadas na psicologia e na biologia, teria pensado desse último desenvolvimento.

\section{Isso importa?}

As pessoas que formam professores e criam currículos não dão muita atenção à ciência da leitura, mas existem razões para pensar que um alinhamento mais estreito entre a ciência e a educação resultaria em melhores resultados? Sempre houve visões concorrentes sobre como a leitura deveria ser ensinada ou se precisaria ser ensinada. Pessoas que tiveram experiências educacionais muito diferentes conseguem se tornar leitores qualificados. Sabemos que a qualidade dos professores tem um enorme impacto nos resultados da educação (por ex., HANUSHEK; RIVKIN, 2006), mas e as diferentes maneiras de ensinar a ler?

Isso deveria importar. A leitura é uma habilidade aprendida, um "ato não-natural" como na frase memorável de Gough. Algumas crianças têm facilidade para aprender a ler, independentemente do que aconteça na sala de aula; muitos já estão no caminho da leitura no início da educação formal. Outras crianças terão dificuldade em aprender a ler independentemente do que aconteça na sala de aula porque são disléxicos: eles têm um distúrbio 
do desenvolvimento que interfere no aprendizado da leitura. Poucos programas de formação de professores oferecem treinamento sério relacionado a distúrbios do desenvolvimento, como dislexia, como as crianças com risco podem ser identificadas e como essas crianças podem ser ajudadas. Enquanto os pesquisadores estão se aproximando das bases neurais e genéticas da dislexia (GABRIELI, 2009), os teóricos da educação ainda estão debatendo se existe dislexia e, no caso de existir, se o fato de saber que uma criança tem o distúrbio deve ter algum impacto nas práticas da sala de aula (ELLIOTT; GIBBS, 2008). Muitas das crianças e adultos que apresentam baixa pontuação nas avaliações nacionais são, sem dúvida, disléxicos cuja condição não foi identificada nem tratada.

Em meio aos extremos há uma grande maioria de crianças para as quais o modo como se ensina a ler é muito importante. Por causa delas devemos estar atentos a como os professores são ensinados em relação à leitura. O principal problema é que muitos dos pressupostos básicos sobre como as crianças aprendem a ler, que guiaram a formação de professores, práticas em sala de aula e desenvolvimento curricular foram refutados pela pesquisa básica que leva à Síntese Moderna. Crenças sobre leitura, aprendizagem e desenvolvimento, reafirmadas ao longo de vários anos nas culturas insulares de escolas de educação, não coincidem com os fatos obtidos usando uma variedade de métodos em laboratório e parâmetros naturalistas. Ao invés de repetir os detalhes analisados nas fontes já citadas, permitam-me tentar capturar a essência do problema.

Todos concordam que as crianças devem adquirir competências básicas relacionadas com o processamento de códigos visuais (por exemplo, reconhecimento das letras, aprendizagem sobre estrutura ortográfica e a relação entre ortografia e fonologia), as quais possibilitam uma base para o desenvolvimento da habilidade de compreender diferentes tipos de textos para diferentes objetivos. Para além dessa observação básica, há duas visões contraditórias.

Os educadores têm presumido que as habilidades básicas são relativamente fáceis de adquirir, mas a compreensão é difícil. A aquisição dessas habilidades básicas é, sobretudo, uma questão de proporcionar um ambiente rico com foco no letramento com atividades que motivem e envolvam a criança. Aprender a ler foi considerado semelhante a aprender a linguagem falada. As crianças não precisam ser explicitamente instruídas em como ler , assim como não precisam de instruções para falar a língua materna. Na prática - em uma turma de pré-escola de crianças de 3 anos de idade na abordagem global - isso significa des-enfatizar instruções relacionadas à aquisição de competências básicas. No ambiente apropriado, repleto de literatura "autêntica" (ao invés de livros escritos com o objetivo de ensinar a ler), atividades de letramento focadas em um engajamento "multissensorial" alargado com livros (por exemplo, ler um livro para a criança, pequenos grupos de crianças lendo o livro em voz alta juntos, fazer cópias pessoais do livro, desenhar imagens do livro, colorir o livro, "escrever" sobre o livro usando escrita inventada, conversar sobre o livro), a criança descobriria os mecanismos. Segundo John Dewey, descobrir como funciona a leitura tem mais valor do que ser ensinado a ler. O papel do professor é promover o letramento, não apenas ensinar a ler.

A compreensão, em contraste, foi considerada difícil. O grande medo era que as crianças pudessem desenvolver habilidades básicas e ainda assim não conseguir compreender textos. (De fato, pensou-se que um foco inicial nos fonemas tornaria mais difícil a criança vir a ser um bom compreendedor). Inspirados por teóricos como Frank Smith (1971, agora na sua sexta edição), os currículos focaram em desenvolver o conhecimento explícito da criança sobre estrutura textual, tipos de inferências, as diversas relações entre autor e leitor, as diversas finalidades de leitura, como monitorar a compreensão e corrigir erros, e assim por diante.

No lado da ciência, a história é completamente oposta. Habilidades básicas são difíceis de adquirir (sobretudo por causa da maneira parcial e abstrata com que os sistemas de escrita representam a linguagem falada) e, portanto, a área em que a instrução mais importa. A 
compreensão, em contraste, depende da experiência prolongada de uso da língua falada e escrita com diferentes objetivos. Ambientes e atividades que proporcionam tal experiência podem, portanto, promover habilidades de compreensão. Ironicamente, esse aspecto de se tornar um leitor hábil tem mais semelhança com a aquisição de língua falada do que com a aquisição de habilidades básicas.

A compreensão leitora depende, inicialmente, do conhecimento que a criança tem da linguagem falada. Aprender uma primeira língua envolve a codificação de informações detalhadas sobre a estrutura estatística dos enunciados aos quais a criança é exposta (SEIDENBERG, 1997). Essa informação é continuamente atualizada durante a vida, através do uso da língua (HASKELL; THORNTON; MACDONALD, 2010). As habilidades de compreensão variam de criança para criança porque existem diferenças individuais enormes com relação à pura quantidade de linguagem falada à qual a criança é exposta, e a gama de itens de vocabulário e estruturas frasais incluídas. Assim, a compreensão leitora pode ser melhorada ao enriquecer o conhecimento da criança em relação à língua falada (HOFF, 2013).

Crianças que recebem as instruções e apoio para adquirir habilidades básicas podem avançar ao ponto de ler textos diversos para fins diversos, aprender por feedback se estão lendo bem ao invés de receber instruções explícitas sobre como compreender a leitura. Promover o desenvolvimento de habilidades através de engajamento e feedback é diferente de ensinar a criança uma meta-teoria da compreensão. Em certo ponto, a relação entre a fala e a escrita se torna recíproca e interativa. O conhecimento da língua falada ajuda a aprender a ler; a criança pode, então, adquirir vocabulário e familiaridade com diversas estruturas gramaticais tanto através da leitura quanto da fala. $O$ que se aprende através da leitura também contribui para o desenvolvimento de habilidades ligadas à língua falada. Para leitores hábeis, os sistemas se tornam intimamente entrelaçados, até mesmo em nível neurológico (PATTAMADILOK et al., 2010).

Em suma, os teóricos do campo educacional tiveram demandas instrucionais versus experimentais para a aquisição de habilidades básicas versus compreensão ao avesso. Gerações de professores foram então ensinadas que as habilidades aparecem naturalmente e que a compreensão exige instrução explícita. Essa inversão tornou a aprendizagem da leitura mais difícil para muitas crianças.

Por fim, devido a esse problema das duas culturas, há pouca oportunidade para focar em como melhor integrar pesquisas básicas com práticas educativas. A ciência da leitura é altamente avançada mas não vem com prescrições sobre práticas educacionais em anexo. Uma coisa é saber como as crianças aprendem a ler e outra é traduzir esse conhecimento para dentro das salas de aula. O relatório NRP oferece uma boa ilustração do zeitgeist ${ }^{27}$. O relatório apresenta um ótimo trabalho ao descrever os principais elementos envolvidos na aprendizagem da leitura e nas evidências que sustentam tais elementos. Não estava dentre suas atribuições abordar a questão educacional, como esses componentes poderiam ser efetivamente abordados dentro de um currículo de leitura integrado e plurianual. Assim, o relatório descreveu a importância de elementos como a consciência fonêmica e vocabulário na leitura para iniciantes, mas não os níveis de competência que são apropriados ao desenvolvimento ou como avaliá-los, ou a efetividade de diferentes métodos instrucionais. Isso criou uma enorme lacuna. É fácil criar currículos supostamente em conformidade com as recomendações do NRP, simplesmente tocando em todos os componentes listados, mesmo se só por um dia. Não houve um diálogo sério sobre as implicações pedagógicas dos dados científicos sintetizados no relatório, um dos principais fatores que contribuem para a falta de impacto da ciência.

\footnotetext{
${ }^{27}$ N.T. Termo alemão utilizado para designar o espírito de uma época, o que foi produzido em um determinado período de tempo.
} 
Volume 15 - Número 2 - ago/dez de 2020

\section{O impacto das variações linguísticas no contexto educacional}

Não pode haver uma discussão séria sobre questões da literacia nos EUA sem considerar as as diferenças de desempenho (achievement gap). $\mathrm{O}$ termo se refere às disparidades na performance acadêmica entre grupos de indivíduos. É usado sobretudo como referência para grupos minoritários - afro-americanos, hispânicos, nativos americanos - comparados aos brancos, mas existem várias outras "diferenças". Há "diferenças" enormes associadas às desigualdades de renda (REARDON, 2011), e há diferenças para outros grupos como a primeira geração de filhos de imigrantes nos EUA comparados com gerações subsequentes. Tais "diferenças" são observadas em leitura, matemática, ciências, e em outras áreas, em uma variedade de índices, incluindo notas, resultados em testes padronizados, o tipo de matérias que os estudantes cursam, taxas de conclusão de ensino médio e ensino superior, e assim por diante (WASHINGTON et al., in press). Meu foco é na diferença de desempenho em leitura e, novamente, se o que nós aprendemos com nossas pesquisas pode ser utilizado nesse sentido ${ }^{28}$.

Também limitarei a atenção à defasagem para os afro-americanos, ainda que as diferenças existam em grupos definidos de várias outras maneiras. Por que separar esse grupo especificamente? Primeiro, porque essa diferença é uma questão fundamental para expressivo número de indivíduos afetados. Segundo, porque é parte de uma longa história de desigualdade racial nos Estados Unidos. Terceiro, porque tem sido foco de atenção de políticos, educadores e economistas há vários anos (JENCKS; PHILLIPS, 1998; EQUITY AND EXCELLENCE COMMISSION, 2013). Quarto, porque essa diferença é persistente. Ela sempre existiu, desde que os dados relevantes começaram a ser coletados, com poucas mudanças apesar dos esforços governamentais desde os programas War on Poverty (Guerra contra a pobreza) e No Child Left Behind (Nenhuma Criança Deixada para Trás) até o programa Race to the Top (Corrida para o Topo). Quinto, é uma área na qual eu conduzo pesquisas (Washington et al.,). Enfim, há várias razões para as diversas diferenças na nossa sociedade. Condições e circunstâncias que são altamente relevantes para um grupo podem ser irrelevantes para outro. Ainda que esse foco seja assegurado, também é essencial reconhecer que isso é parte de um fenômeno muito mais amplo, que afeta diversos grupos de pessoas.

As causas da defasagem na leitura dos afro-americanos (e outros grupos) são obviamente complexas e não podem ser abordadas de maneira completa aqui (ver RICHARDSON, 2008; MAGNUSON; DUNCAN, 2006; BARTON; COLEY, 2009; WASHINGTON et al., no prelo). Trata-se de um tema sensível, tendo relação com generalizações sobre os grupos, dentro dos quais há grandes variações. O que está sendo dito aqui não pode ser entendido como aplicável a todos os membros de um grupo, ou a algum indivíduo dentro do grupo. Pode ser perigoso levantar questões sobre as diferenças dos grupos em contextos que não permitem explorações sérias e trocas de ideias ${ }^{29}$. Eu também sei, por experiência, que qualquer coisa dita sobre esse assunto, por mais que seja um argumento fundamentado, com evidências e colocado cuidadosamente com as devidas qualificações, pode ser interpretado com fins políticos que os pesquisadores não conseguem controlar. Meu objetivo aqui é limitado: estabelecer a relevância da pesquisa em leitura e linguagem para entender e potencialmente amenizar essa defasagem. Meu único interesse pessoal é encorajar outras pessoas a conduzir pesquisas na área, pelas mesmas razões pelas quais eu me envolvi: porque

28 [8] Dados básicos sobre a diferença de desempenho em leitura, como mensurados na Avaliação Nacional de Progresso Acadêmico (NAEP), podem ser encontrados no resumo dos resultados de 2011, pp. 15 e 44 (http://nces.ed.Gov/Nationsreportcard/pubs/main2011/2012457.asp).

29 [9] Como exemplificado pelas conjecturas do então Reitor da Universidade de Harvard, Lawrence Summers, sobre possíveis diferenças genéticas ligadas ao gênero na aptidão matemática. (http://www.harvard.edu/president/speeches/summers 2005/nber.php). Acredito que um artigo em uma revista como esta forneça um contexto apropriado. 
esses assuntos são cientificamente interessantes; porque a pesquisa existente em leitura e aquisição de linguagem é relevante; porque há uma lacuna de pesquisa na medida em que os fatores e condições específicas às crianças afro-americanas e sua aquisição de leitura são pouco estudadas; porque a defasagem pode ser abordada por pesquisadores que estudam outros aspectos da aquisição de linguagem e leitura; e porque as consequências dos insucessos na leitura podem ser devastadoras.

\section{Análises econométricas: qual é a peça que falta?}

A base da disparidade entre brancos e negros na leitura tem sido extensivamente estudada por economistas e sociólogos. Diversas análises importantes usaram uma base de dados vasta e disponível publicamente, o "Early Childhood Longitudinal Study" (Estudo Longitudinal da Primeira Infância) (ECLS; http://nces.ed.gov/ecls). Esses dados foram retirados de várias entrevistas com um grande número de indivíduos (cerca de 20.000), adicionados aos resultados de instrumentos de avaliação. Em conformidade com outra pesquisa, as informações do ECLS mostram que há uma disparidade no início da escolarização: crianças afro-americanas estão aquém na questão das habilidades de leitura e de pré-leitura na pré-escola (DUNCAN; MAGNUSON, 2005). Pesquisadores buscaram identificar as bases dessa disparidade ao determinar quais fatores na base de dados explicam essa diferença. Fryer e Levitt (2004) mostraram que seis fatores (de aproximadamente cem que foram considerados) eram responsáveis pela diferença no começo da escolaridade no sentido estatístico: uma medida composta de status socioeconômicos, idade da criança ao ingressar na pré-escola, peso de nascimento, idade da mãe no primeiro parto, se a mãe era usuária de algum tipo de programa governamental de assistência social (WIC), e o número de livros infantis em casa. Esses resultados são correlacionais e estão abertos a interpretações diversas. $\mathrm{O}$ grupo de fatores em questão parece explorar, principalmente, problemas relacionados a status socioeconômico e sequelas, tais como pior condição de saúde ou de serviços de saúde e menos recursos como livros em casa.

Os resultados de pesquisas adicionais com uma onda de dados coletados rendeu a descoberta surpreendente de que o tamanho da disparidade aumenta na terceira série (FRYER; LEVITT, 2006; ver também MAGNUSON; DUNCAN, 2006). A interpretação causal é, novamente, incerta; a escolarização poderia tanto estar exacerbando a disparidade, quanto ter seus efeitos positivos superados pelos crescentes impactos de outros fatores. Em ambos casos, a escolarização não estaria atuando como o "grande fator equalizador" ${ }^{30}$. Além disso, os seis fatores responsáveis pela disparidade na pré-escola, não eram responsáveis pela disparidade na terceira série, assim como outros fatores na base de dados. Fryer e Levitt assinalam que "nenhuma das explicações que nós examinamos, incluindo diferenças sistemáticas na qualidade escolar em relação às raças, explicam, de forma convincente, a trajetória divergente de estudantes negros". (p. 447)

O fato de que os fatores relacionados ao SES não responderam pelo aumento na disparidade é coerente com outros resultados, indicando que a defasagem na leitura não está circunscrita a indivíduos com menor renda. Como já mencionado, a performance no NAEP é afetada pela condição socioeconômica, como mostrou o índice de elegibilidade para o almoço

\footnotetext{
${ }^{30}$ [10] Esses dados desmentem uma crença acalentada. Então: "A educação, além de todos os outros dispositivos de origem humana, é um grande equalizador das condições dos homens - a roda do equilíbrio da máquina social" (MANN, 1848). E agora: "Na América, a educação ainda é o grande equalizador" (Arne Duncan, Secretário de Educação dos Estados Unidos, 2011) (http://www.ed.gov/news/speeches/remarks-us-secretary-education-arneduncan-he-education-trust-conference). Devemos também considerar se a educação, como ocorre nas escolas americanas e como é financiada, exacerba as diferenças entre os grupos.
} 
subsidiado. No entanto, a disparidade entre brancos e negros é bastante consistente nos três níveis dessa medição (VANNEMAN et al., 2009, p.33). Outros estudos descobriram que a disparidade ocorre tanto na população negra com renda média quanto com renda baixa (GOSA; ALEXANDER, 2007). Novamente, deve-se enfatizar que com distribuições sobrepostas e correlações imperfeitas, há indivíduos que divergem dessas tendências generalizadas, incluindo negros com menor status socioeconômico cujos resultados em leitura estão no mesmo nível de brancos com maior status socioeconômico que apresentam bons resultados, um ponto que Magnuson e Duncun (2006, p.368) realçam, considerando que quase um quarto dos estudantes negros de pré-escola no ECLS-K obtiveram resultados melhores do que a média para estudantes brancos. No entanto, as diferenças entre os grupos merecem atenção.

Encontra-se aqui um quebra-cabeça. Estamos à procura de um fator ausente (ou fatores) com as seguintes características:

1. Contribui para o crescente déficit do K-3.

2. Afeta indivíduos de diferentes níveis de SES.

3. Não é capturado pelas medidas incluídas em conjuntos de dados como o ECLS.

O que poderia ser? Uma possibilidade é a linguagem. Há dois elementos a considerar. Um é o conhecimento da língua falada, que varia entre as crianças, aliado à várias outras habilidades e capacidades. A outra é a natureza dos códigos linguísticos aos quais as crianças estão expostas. Vou me concentrar em diferentes dialetos do inglês, embora surjam problemas semelhantes em relação à exposição a diferentes línguas. Considero cada um desses elementos - gerais de linguagem e relacionados a dialetos - por sua vez.

Há pouquíssimos dados sobre as línguas faladas pelas crianças nas pesquisas em larga escala, como o ECLS, Study of Early Child Care and Youth Development or the Children of the National Longitudinal Survey of Youth survey $79^{31}$. A pesquisa ECLS-K conduzida por Fryer e Levitt inclui um item que avalia se o inglês é falado em casa, além de uma "avaliação cognitiva" consistindo em itens retirados de uma variedade de testes padronizados, mas nenhuma avaliação direta das características da língua da criança. e o ambiente linguístico. No entanto, há um corpo substancial de evidências sobre o impacto desses fatores no desempenho escolar das crianças, particularmente na leitura (McCARDLE; SCARBOROUGH; CATTS, 2001). As crianças variam consideravelmente em relação ao conhecimento dos componentes da língua falada, incluindo a amplitude do vocabulário, morfologia e sintaxe (BATES; DALE; THAL, 1995). As pessoas geralmente se referem a diferenças na "habilidade" verbal, mas a riqueza relativa da linguagem das crianças é afetada por fatores exógenos e, portanto, esse termo parece inadequado. Alguns se referem à "qualidade" da linguagem falada, mas, nesse contexto, o termo evoca a ideia desacreditada de que o inglês afro-americano é inerentemente inferior. $\mathrm{Na}$ falta de um termo melhor, irei me referir sempre que possível às diferenças no conhecimento geral da língua falada. Essas diferenças podem surgir de fatores constitucionais, ambientais e socioculturais.

O fator mais amplamente estudado é o SES. Diferenças no conhecimento linguístico associado ao SES foram documentadas no famoso estudo de Hart e Risley (1995; ver também HANSEN; JOSHI, 2007; HOFF, 2013). As crianças têm dificuldade em aprender palavras, estruturas gramaticais e convenções de discurso aos quais não estão expostas. $\mathrm{O}$ vocabulário, em particular, está fortemente relacionado ao progresso no aprendizado da leitura (NRP, 2000). Em suma, o sucesso das crianças em fazer a transição para a leitura depende fortemente de seu conhecimento da língua falada, que varia entre os indivíduos e está associada com diferenças no SES (FERNALD; MARCHMAN, 2011). As crianças afro-americanas são super-

\footnotetext{
31 [11] Estudo NICHD de Assistência à Primeira Infância e Desenvolvimento da Juventude ou o Filhos da Pesquisa Nacional Longitudinal da Juventude 79. NICHD Study of Early Child Care and Youth Development,

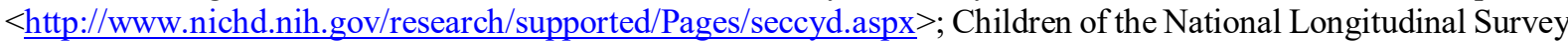
of Youth 79 survey, $<$ http://www.bls.gov/nls/nlsy $79 . h t m>$.
} 
Volume 15 - Número 2 - ago/dez de 2020

representadas na extremidade inferior da distribuição do SES; portanto, estão desproporcionalmente sujeitas aos efeitos dessa posição na linguagem.

Todavia, este argumento é inconclusivo. Os fatores relacionados ao SES que Fryer e Levitt identificaram podem ser relevantes, em parte, devido à sua associação com diferenças referentes ao estímulo na língua, mas isso não pode ser algo determinado, já que o conjunto de dados ECLS-K não inclui medidas de vocabulário da criança ou do seu cuidador (ou outros aspectos da linguagem falada). As relações entre os seis fatores e o conhecimento da criança da língua falada são indiretas. Além disso, esses fatores foram responsáveis por diferenças no início da escolarização, mas não pelo crescimento da lacuna durante a terceira série.

Portanto, quaisquer que sejam os aspectos do ambiente linguístico que eles possam estar percebendo, não são suficientes para explicar este aumento. Finalmente, há o fato de que a diferença de resultados não se limita à menor coorte do SES. Desembaraçar a complexa relação entre SES e a lacuna dos resultados continua sendo o foco da pesquisa (DUNCAN; MAGNUSON, 2012). Uma leitura cautelosa da literatura existente sugere que deve haver outros fatores envolvidos e que as contribuições da variabilidade da linguagem precisam ser avaliadas mais diretamente

Uma consideração adicional, não abordada nos estudos do ECLS, é a natureza do código linguístico ao qual a criança está exposta em um dialeto particular. Dialetos são variantes de uma língua, falados por indivíduos agrupados por região, etnia, raça, renda e outros fatores (CHAMBERS; TRUDGILL, 1998). Todo falante nativo de uma língua aprende um dialeto. A língua inglesa tem muitos dialetos, identificáveis em diferentes formas (por exemplo, inglês americano x inglês britânico; dialetos regionais nesses países).

Nos Estados Unidos, uma grande divisão acontece entre o chamado "standard" (padrão) ou "mainstream" (convencional) do Inglês Americano (SAE) e o Inglês Afro-americano (AAE). Como em outros países, o dialeto ser tratado como "padrão" não é uma questão linguística, mas determinada por considerações demográficas, culturais e políticas. AAE e SAE se sobrepõem - ambos representam versões da língua inglesa - mas também se diferem em relação a elementos específicos de fonologia, morfologia, léxico, sintaxe e discurso/pragmática (RICKFORD, 1999). Embora seja importante reconhecer que o AAE possui variantes regionais, assim como a SAE (GREEN, 2002; WOLFRAM; SCHILLING-ESTES, 2006). Além disso, os falantes variam na medida em que utilizam características da AAE (uma dimensão denominada densidade de dialeto; ver THOMPSON; CRAIG; WASHINGTON, 2004); portanto, a extensão em que o AAE se difere do SAE também varia. O AAE é usado pela maioria dos afroamericanos, em densidades variadas, de acordo com os níveis do SES (WASHINGTON, 1996). A questão, então, é se o uso do AAE contribui para o déficit de leitura.

A pesquisa sobre essa questão data de muitas décadas (ver WASHINGTON et al., no prelo, para uma revisão mais detalhada). Uma pergunta é se um falante da AAE seria prejudicado porque o dialeto é deficiente de alguma maneira. Esse questionamento foi resolvido decisivamente através dos estudos linguísticos sobre AAE conduzidos por Labov (1972) e posteriormente por muitos outros pesquisadores (RICKFORD; SWEETLAND; RICKFORD, 2004). A pesquisa situou apropriadamente o AAE no contexto da variação dialética, como ocorre diversas línguas ao redor do mundo. Uma das grandes contribuições desse estudo foi estabelecer a excepcionalidade da AAE enquanto um exemplo de variação linguística (RICKFORD; RICKFORD, 2000). Compreender se o uso do dialeto afeta ou não o desempenho escolar não é uma questão sobre o status linguístico da AAE. O problema não resolvido é entender se o uso do dialeto minoritário tem impacto devido às condições que o envolvem. Especificamente, o uso do AAE pode afetar a capacidade da criança de se beneficiar de experiências educacionais devido a fatores sociológicos e culturais (por exemplo, AAE é um dialeto de "baixo status"; livros são escritos em SAE; adquirir habilidades em SAE é um 
objetivo educacional nas escolas americanas). São essas condições que tornam as diferenças entre os dialetos relevantes, não porque elas são significativas em termos linguísticos.

A pesquisa de Labov estimulou outro estudo sobre o possível impacto da AAE no desenvolvimento das habilidades de leitura de crianças afro-americanas. A maioria dos primeiros estudos demonstrou que o uso do dialeto teve pouco efeito na compreensão leitora (WASHINGTON et al., no prelo). Assim, concluiu-se que o importante era a qualidade da experiência linguística, independente do dialeto. Considerou-se que esses resultados colocaram um fim ao problema sobre o impacto da AAE na aquisição da leitura, entretanto, de forma prematura, em minha opinião. Os primeiros estudos não se sustentam de acordo com os padrões modernos de pesquisa e as fortes conclusões baseadas neles precisam ser reexaminadas. Nos últimos anos, pesquisadores começaram a rever a questão, usando o que foi aprendido sobre leitura, linguagem, desenvolvimento e cognição nas últimas décadas para gerar hipóteses mais específicas que podem ser testadas usando métodos de pesquisa mais eficazes. O tópico continua pouco abordado e muitos problemas empíricos ainda não foram solucionados.

Uma questão importante é a seguinte: se a variação da linguagem é um elemento significativo na disparidade dos resultados, até que ponto ela envolve aspectos gerais da linguagem versus aspectos da linguagem relacionados ao dialeto? O desempenho precoce da leitura está diretamente relacionado ao conhecimento da linguagem falada. Essa relação é geral, aplicando-se a várias línguas e, dentro de uma língua, em variantes dialetais. Se as crianças pequenas diferem no que diz respeito a habilidades como consciência fonológica, capacidade de analisar palavras faladas no nível fonêmico, amplitude do vocabulário e compreensão da linguagem falada, esses são os aspectos relevantes, e não qual variante de uma língua eles falam (TERRY, no prelo; TERRY; SCARBOROUGH, 2011).

Ademais, é possível que haja efeitos relacionados ao dialeto nos resultados da leitura. Tais efeitos podem surgir de uma variedade de fatores que emergem quando as diferenças linguísticas entre os dialetos convergem com os fatores extralinguísticos referentes às condições educacionais e socioculturais sob as quais os dialetos são usados. As possibilidades gerais de língua e das relações com o dialeto não são mutuamente exclusivas. Além disso, elas podem não ser independentes; por exemplo, a aquisição de uma habilidade geral da língua pode sofrer influência de fatores relacionados ao dialeto. As interferências gerais de um dialeto também podem ser difíceis de identificar porque a capacidade geral de comunicação de uma criança se manifesta no uso de um dialeto específico. Ainda, pode haver vantagens na exposição a múltiplos dialetos, análogos àqueles associados à exposição a diferentes línguas (BIALYSTOK et al., 2009), embora essa possibilidade raramente seja considerada.

Essas questões podem ser ilustradas no tocante ao conhecimento do vocabulário, um fator que tem sido o foco de muitas pesquisas e é conhecido por ter um grande impacto na aquisição da leitura. É fato que as línguas consistem em inventários de palavras (entre outros elementos). A amplitude do vocabulário, no entanto, é característica de cada criança - o que ela sabe sobre esse componente da língua falada - não o dialeto falado. Essa observação sugere que a pesquisa deve se concentrar no conhecimento da criança sobre as propriedades da língua falada, como vocabulário, independentemente do dialeto.

Um fator possivelmente complicador é que as diferenças com a experiência da linguagem, como o uso de um dialeto minoritário, exposição e conhecimento variados do dialeto convencional e uso do dialeto no contexto escolar, podem afetar a aquisição pela criança de elementos "gerais" da língua falada. Um fator como a extensão do vocabulário precisa ser considerado não apenas enquanto um preditor quantitativo dos resultados da leitura, mas também no que diz respeito a uma teoria de como esse conhecimento é adquirido. Desse modo, poderia ser determinado se ou em que medida aspectos específicos da experiência dialética são importantes. A aquisição de vocabulário é afetada pelas propriedades de um dialeto ou pela necessidade de acomodar dois dialetos? Tais efeitos são positivos, negativos ou ambos? Os 
efeitos diferem dependendo do nível de desenvolvimento da criança? Eles são modulados por diferenças individuais nas capacidades cognitivas, como a função executiva? Todos esses questionamentos ainda não são bem compreendidos. A literatura bilíngue sugere que é válida a sua abordagem. Muitos estudos evidenciam que crianças bilíngues em idade pré-escolar têm vocabulários menores em cada idioma do que falantes monolíngues comparáveis (BIALYSTOK; LUK; KWAN, 2005), o que interfere no aprendizado da leitura em um dos idiomas. Esses efeitos surgem de condições relevantes para a aprendizagem das crianças, e não das propriedades das línguas em si e estão igualmente presentes nos níveis do SES. A carga bilíngüe não é insuperável, mas o tempo de desenvolvimento pode ser afetado, criando outra "lacuna", bem como a emergência de vantagens bilíngues (BIALYSTOK et al., 2009). Problemas análogos podem surgir para crianças que falam AAE e que estão aprendendo a ler em SAE.

Como ilustração, considere a exclusão opcional de consoantes finais ao pronunciar algumas palavras no AAE. Uma conseqüência é que uma determinada palavra, $C O L D^{32}$ por exemplo, pode ser pronunciada diferentemente, no nível fonêmico, nos dois dialetos. A exclusão das consoantes finais também cria homofonia adicional: palavras como COLD e COAL têm pronúncias diferentes (no nível fonêmico) no SAE, mas podem ser homofônicas no AAE. Será que as diferenças entre os dialetos têm algum impacto no aprendizado ou na leitura de idiomas? $\mathrm{Ou}$ as diferenças são irrelevantes? Acho que não sabemos. A existência de pronúncias alternativas nos dialetos pode criar um problema mais complexo na aprendizagem de palavras, ou pode não ser mais difícil do que assimilar diferenças na pronúncia decorrentes do tom, da velocidade da fala e assim por diante. Um aumento no número de homofones pode facilitar a aquisição de vocabulário (menos formas fonológicas distintas para aprender) ou dificultar (porque a criança precisa usar outros mecanismos para desambiguar homofones). Talvez o impacto funcional seja trivial. Essas perguntas sem respostas sugerem que seria prematuro tratar a amplitude do vocabulário como um fator linguístico geral independente da experiência dialética.

Considerando as limitadas evidências, acredito que seria mais um erro precoce concluir, neste ponto, que a experiência dialética não tem impacto significativo sobre a leitura ou em outros aspectos do desempenho escolar. Snow et al. (1991) observaram que as diferenças entre a língua falada em casa e a língua falada na escola poderiam impactar o aprendizado das crianças. Para os falantes do dialeto convencional, os dialetos da casa e da escola são os mesmos. Para os falantes do dialeto minoritário AAE, os dialetos da casa e da escola diferem em graus variados. Assim, o uso do dialeto é consistente entre os contextos de um grupo, mas não do outro. Os falantes do AAE precisam aprender sobre o dialeto convencional e usar os dois dialetos ao mesmo tempo em que aprendem a ler, escrever e fazer aritmética. Os falantes do SAE não têm demandas adicionais relacionadas à língua. Os falantes do dialeto minoritário claramente precisam trabalhar mais arduamente para ter êxito. No entanto, eles são avaliados com base nas mesmas medidas de performance que os falantes do SAE. Partir do pressuposto de que essa análise está correta, significa que a disparidade não é tratada porque está embutida, garantida por circunstâncias prevalecentes não relacionadas à validade lingüística do dialeto ou às capacidades da criança ${ }^{33}$. Em outras palavras, se por analogia para a análise de Fryer e Levitt,

\footnotetext{
${ }^{32}$ N.T.: Este exemplo pode ser pensado em português através das diferenças entre a língua escrita e a língua falada, que muitas vezes geram dificuldades para as crianças que estão começando a ler e escrever. $\mathrm{O}$ fato de que, na maioria das vezes, excluímos da fala o "R" final do infinitivo dos verbos como em "trabalhar", bem como a letra "U" no final da conjugação da primeira pessoa de alguns verbos, faz com que a frase "Eu vou trabalhar amanhã", na linguagem falada se torne "eu vô trabalhá amanhã".

${ }^{33}$ [12] Devo esta observação a Julie Washington, quem expôs esse ponto com grande clareza e impacto. A linha de chegada pode estar no mesmo local, mas os caminhos para chegar lá não têm o mesmo comprimento ou dificuldade.
} 
Volume 15 - Número 2 - ago/dez de 2020

a sobrecarga associada à acomodação das diferenças de dialetos foi de alguma forma excluída como um fator no experimento natural; a disparidade nos primeiros anos escolares seria muito mais estreita do que crescente.

As diferenças entre dialetos podem afetar potencialmente a capacidade das crianças de se beneficiarem da experiência em sala de aula em vários aspectos. Por exemplo, um professor que fala SAE pronuncia muitas palavras de maneira diferente da criança e usa construções morfológicas e sintáticas igualmente diferentes. É de se esperar que o processamento adicional e a demanda de atenção associadas à compreensão de expressões no dialeto menos familiar e à alternância entre dialetos interfiram na oportunidade da criança de aprender com o que está sendo dito. O impacto seria exacerbado se o contexto da sala de aula for barulhento (literalmente e no sentido teórico da informação), prejudicando a qualidade dos sinais linguísticos. O efeito seria semelhante a impor um atraso no processamento online de enunciados falados. Essas demandas podem, ao mesmo tempo, promover o desenvolvimento de outras capacidades como a função executiva. Além disso, é possível que haja falhas de comunicação do lado oposto: pode ser difícil para um professor que fala $\mathrm{SAE}$ e não conhece o dialeto $\mathrm{AAE}$, entender a criança que se comunica em AAE. O professor também pode fazer uso de convenções de discurso (por exemplo, atos indiretos de fala) com os quais a criança não está familiarizada, ou ainda, poderá interpretar mal as convenções de discurso da própria criança.

Existem maneiras específicas pelas quais as diferenças de dialeto podem afetar o aprendizado da leitura. A criança fala um dialeto, mas os livros e outros materiais didáticos são escritos em outro dialeto, impondo novamente demandas adicionais de aprendizagem e processamento em comparação com a criança que faz uso do mesmo dialeto para ambos. Uma boa comparação é com crianças que apresentam deficiência auditiva, signatárias nativas de ASL (American Sign Language - Língua Americana de Sinais), fluentes e com habilidades verbais elevadas, com amplo vocabulário que exibem um alto grau de variedade e complexidade sintática - mas são leitores fracos. A "disparidade" na leitura para os deficientes auditivos ocorre, em parte, porque eles estão aprendendo a ler em inglês, uma língua diferente. É importante pontuar as diferenças entre ambas as situações (por exemplo, as diferenças entre ASL-inglês são maiores que as diferenças entre os dialetos em inglês; embora o uso de diferentes dialetos não esteja associado à presença ou ausência de um déficit de percepção, como perda auditiva), a analogia é apropriada.

E quanto a aquisição das habilidades básicas de leitura? $\mathrm{O}$ desafio principal do leitor iniciante é aprender como a língua falada, que ele conhece, corresponde ao código escrito que ele está aprendendo. Fazer essa conexão é não é fácil para muitas crianças, por razões que foram investigadas em profundidade (NRP, 2000). Ler um alfabeto implica em aprender a tratar as palavras faladas como se fossem fonemas distintos. As unidades do código escrito (letras e dígrafos) podem, dessa forma, ser mapeadas em unidades no código falado (fonemas). Chegar a essa abstração é difícil. A tarefa é ainda mais complicada por inconsistências nos mapeamentos entre a ortografia e som em inglês, se tornando ainda mais complexa quando um número substancial de palavras é pronunciado de maneira diferente no nível fonêmico nos dois dialetos. Considere apenas o subconjunto de palavras em AAE no qual a consoante final pode ser descartada (por exemplo, GOLD $\rightarrow /$ goUl /, BEST $\rightarrow /$ bes $/$ ). Um professor explica que a palavra "ouro" se escreve G-O-L-D. Para uma criança que fala SAE, a lição é sobre o princípio alfabético e as correspondências entre quatro letras e quatro fonemas. O que está sendo ensinado a uma criança que fala com AAE que pronuncia a palavra / goUl /? Que existem maneiras diferentes de pronunciar a palavra? Que a ortografia direcionada para uma pronúncia tem a letra / d / pronunciada no final, enquanto para a outra a letra é silenciada? As pronúncias alternativas criam inconsistências adicionais nos mapeamentos entre grafema (ortografia) e fonema (som). O problema de aprendizagem fica ainda mais complicado porque essa exclusão não é obrigatória e, portanto, pode ser usada para uma determinada palavra apenas em parte do tempo, 
Volume 15 - Número 2 - ago/dez de 2020

ou apenas para algumas palavras com grafia semelhante (por exemplo, palavras que terminam com-OLD).

Em síntese, a necessidade de acomodar ambos os dialetos pode significar uma grande carga adicional para os aprendizes. O potencial para os fatores relacionados ao dialeto afetarem a aprendizagem - e a necessidade de se determinar onde as diferenças entre os dialetos têm e não têm um impacto significativo, seja positivo ou negativo - não invalida a relevância da variabilidade independente do dialeto nas habilidades da língua falada. . Obviamente, ambos poderiam exercer influência, criando, no pior dos casos, um golpe duplo debilitante. No entanto, ainda não sabemos até que ponto esses efeitos ocorrem e em que medida eles geram impacto.

O que chama a atenção no dialeto é o quão pouco é abordado nos Estados Unidos em comparação com outros países. A variação de dialeto não é específica para afro-americanos ou ingleses, mas as diferenças de dialeto parecem ter maior destaque neste país do que em outros lugares. Existem grandes variantes de dialetos em países como Finlândia e Alemanha, onde os níveis de literacia são mais altos do que nos EUA. Embora cada situação tenha suas especificidades, os principais desafios são os mesmos. Parece que esses países lidam melhor com o reconhecimento e adaptação às diferenças de dialetos. Será que os educadores estão mais familiarizados com os dialetos e seu potencial de impacto? A formação de professores inclui questões relacionadas ao dialeto? Existe menos preconceito relacionado ao dialeto nesses países? Existe maior exposição a dialetos alternativos antes do início da escolaridade? Sabemos que o que funciona em um país não pode simplesmente ser transposto para outro, onde as circunstâncias relevantes são diferentes. No entanto, há informações pertinentes ao examinar como essas questões são tratadas em outros países e línguas. Esse esforço pode sugerir maneiras de mudar as condições culturalmente determinadas que contribuem para a disparidade na leitura.

Olhando para o futuro, a pesquisa sobre as disparidades no desempenho da leitura pode se beneficiar dos estudos dos distúrbios de leitura e linguagem. Investigações sobre a dislexia, por exemplo, saíram do foco em causas únicas (por exemplo, um déficit visual ou fonológico) para a visão de que os resultados surgem dos efeitos agregados de um conjunto de fatores de risco (SNOWLING; HULME, 2011; SNOWLING; HAYIOU-THOMAS, 2006). Cada fator gera probabilidades, no sentido de que ele próprio não garante um resultado único. Os fatores também variam em graus de gravidade e impacto relativo, que juntos, geram uma série de resultados comportamentais. A ligação crucial entre os fatores de risco e os resultados é fornecida por teorias da leitura que especificam as principais habilidades e como elas são aprendidas. Por analogia, os resultados negativos de leitura observados na disparidade surgem de uma variedade de fatores de risco que também são probabilísticos, variam em gravidade e impacto, interagem de maneiras complexas, são diferencialmente passíveis de intervenção e produzem uma ampla gama de resultados individuais. Os fatores de risco relevantes para as crianças afro-americanas nas escolas americanas incluem conhecimento da língua falada (habilidades "gerais"), experiência na língua (por exemplo, uso de dialeto, exposição e conhecimento do dialeto alternativo, demandas cognitivas da troca de dialeto) adequação das respostas educacionais à variação de linguagem, pobreza, entre outros. É necessário vincular esses fatores de risco aos componentes específicos da leitura e como eles são adquiridos.

\section{Conclusões}

A defasagem na leitura é resultante de causas variadas. Meu objetivo é sugerir que esse sério problema social pode se beneficiar mais dos tipos de pesquisa que realizamos enquanto cientistas que estudam a leitura e a linguagem. A leitura é frequentemente vista como secundária em relação à língua falada e de pouco interesse linguístico. De fato, a leitura não evoluiu nas 
espécies, mas uma vez que a tecnologia se tornou disponível para muitas pessoas, ela se tornou uma expressão tão central da nossa capacidade discursiva, transformando a forma como a linguagem é usada. Existem cientistas que estudam profundamente a leitura, e fizemos um progresso considerável no entendimento dessa habilidade. No entanto, a investigação sobre como a leitura funciona e os determinantes dessa habilidade, invariavelmente retomam as questões sobre a linguagem falada. Busco assinalar que nossa pesquisa é altamente relevante para um problema social de enorme importância. Os desafios são intimidadores e a necessidade é imensa.

\section{Referências}

ADAMS, M. Beginning to read. Cambridge, MA: MIT Press, 1990.

ALLINGTON, R. L. Big brother and the national reading curriculum: how ideology trumped evidence. Portsmouth, NH: Heinemann, 2002.

ALLINGTON, R. L.; WOODSIDE-JIRON, H. The politics of literacy teaching: How "research" shaped educational policy. Educational Researcher, 28, p. 4-13, 1999.

ARO, M.; WIMMER, H. Learning to read: English compared to six more regular orthographies. Applied Psycholinguistics, 24, p. 621-635, 2003.

ASSOCIATION OF MASTERS OF THE BOSTON PUBLIC SCHOOLS. Remarks on the seventh annual report of the Hon. Horace Mann, secretary of the Massachusetts Board of Education. Boston, MA: Charles C. Little and James Brown, 1844.

AU, K. H. Social constructivism and the school literacy learning of students of diverse backgrounds. Journal of Literacy Research, 30, p. 297-319, 1998.

BARTON, D.; HAMILTON, M. Literacy practices. In: BARTON, D.; HAMILTON, M.; IVANIC, R. (Eds.) Situated literacies: Theorising reading and writing in context. Milton Park, England: Routledge, p. 7-15, 1999.

BARTON, P. E.; COLEY, R. J. Parsing the achievement gap II. Princeton, NJ: Policy Information Center, Educational Testing Service, 2009.

BATES, E.; DALE, P. S.; THAL, D. Individual differences and their implications for theories of language development. In: FLETCHER, P.; MACWHINNEY, B (Eds.), Handbook of child language. Oxford, England: Basil Blackwell, p. 96-151, 1995.

BIALYSTOK, E.; et al. Bilingual minds. Psychological Science in the Public Interest, 10, p. 89-129, 2009.

BIALYSTOK, E.; LUK, G.; KWAN, E. Bilingualism, biliteracy, and learning to read: Interactions among languages and writing systems. Scientific studies of reading, 9, p. 43-61, 2005.

BORING, E. G. A history of introspection. Psychological Bulletin, 50, p. 169-189, 1953.

CHAMBERS, J. K.; TRUDGILL, P. Dialectology. $2^{\text {a }}$ ed. Cambridge, England: Cambridge University Press, 1998.

COLES, G. Misreading reading: The bad science that hurts children. Portsmouth, NH: Heinemann, 2000.

COWEN, J. E. A balanced approach to beginning reading instruction: A synthesis of six major U.S. research studies. Newark, DE: International Reading Association, 2003.

COX, D.; MEYERS, E.; SINHA, P. Contextually evoked object-specific responses in human visual cortex. Science, 304, p. 115-117, 2004.

CREMIN, L. A. American education: The metropolitan experience, 1876-1980. New York, NY: Harper Collins, 1988.

DANIELS, P. T.; BRIGHT, W. The world's writing systems. Oxford, England: Oxford University Press, 1996. 
Volume 15 - Número 2 - ago/dez de 2020

DUKE, N. K.; MARTIN, N. M. 10 things every literacy educator should know about research. The Reading Teacher, 65, p. 9-22, 2011.

DUNCAN, G. J.; MAGNUSON, K. A. Can family socioeconomic resources account for racial and ethnic test score gaps? The Future of Children, 15, p. 35-54, 2005.

DUNCAN, G. J.; MAGNUSON, K. Socioeconomic status and cognitive functioning: Moving from correlation to causation. Wiley Interdisciplinary Reviews: Cognitive Science, 3, p. 377386, 2012.

DURGUNOGLU, A. Y. How the language's characteristics influence Turkish literacy development. In: JOSHI, M.; AARON, P. G. (Eds.) Handbook of orthography and literacy. Mahwah, NJ: Erlbaum, p. 219-230, 2006.

ELLIOTT, J. G.; GIBBS, S. Does dyslexia exist? Journal of Philosophy of Education, 42, P. 475-491, 2008.

EQUITY AND EXCELLENCE COMMISSION. For each and every child-a strategy for equity and excellence. Disponível em: $<$ http://www.foreachandeverychild. org/60565_EEC_(508)_rev.pdf> $>2013$

FERNALD, A.; MARCHMAN, V. A. Causes and consequences of variability in early language learning. In: Experience, variation, and generalization: Learning a first language (trends in language acquisition research). Amsterdam, the Netherlands: John Benjamins, p. 181-202, 2011.

FINN, C. A Sputnik moment for US Education. Wall Street Journal, December 8, 2010.

FRYER, R. G.; LEVITT, S. D. The black-white test score gap through third grade. American Law and Economics Review, 8, p. 249-281, 2006.

FRYER, R. G.; LEVITT, S. D. Understanding the black-white test score gap in the first two years of school. Review of Economics and Statistics, 86, p. 447-464, 2004.

GABRIELI, J.D.E. Dyslexia: A new synergy between education and cognitive neuroscience. Science, 325, p. 280-283, 2009.

GEE, J. P. Thinking, learning, and reading: The situated sociocultural mind. In: KIRSHNER, D. I.; WHITSON, J. A. (Eds.) Situated cognition: Social, semiotic, and psychological perspectives. Mahwah, NJ: Lawrence Erlbaum Associates, p. 235-259, 1997.

GIBSON, E.; LEVIN, H. The psychology of reading. Cambridge, MA: MIT Press, 1978.

GOLDIN-MEADOW, S.; MAYBERRY, R. How do profoundly deaf children learn to read? Learning Disabilities Research \& Practice, 16, p. 222-229, 2001.

GOSA, T. L.; ALEXANDER, K. L. Family disadvantage and the educational prospects of better off African American youth. Teachers College Record, vol. 109, no 2, p. 285-321, 2007. GOUGH, P. B.; HILLINGER, M. L. Learning to read: an unnatural act. Bulletin of the Orton Society, 30, p. 179-196, 1980.

GOVERNMENT ACCOUNTING OFFICE. Poverty in America. Report GAO-07-344. Washington, DC: Author. 2007.

GREEN, L. J. African American English: A linguistic introduction. Cambridge, England: Cambridge University Press, 2002.

GROSSEN, B. 30 years of research: What we now know about how children learn to read. Disponível em: < http://www.eric.ed.gov/PDFS/ED415492.pdf $>$. 1997.

HANLEY, J. R.; et al. How long do the advantages of learning to read a transparent orthography last? An investigation of the reading skills and reading impairment of Welsh children at 10 years of age. Quarterly Journal of Experimental Psychology, 57, p. 1393-1410, 2004.

HANSEN, K.; JOSHI, H. Millennium Cohort Study second survey: A user's guide to initial findings. Centre for Longitudinal Studies, Institute of Education, University of London, London, $\quad 2007 . \quad$ Disponível em:

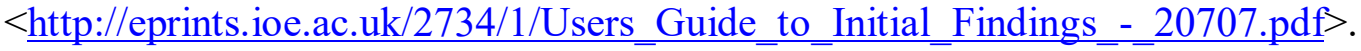


Volume 15 - Número 2 - ago/dez de 2020

HANUSHEK, E. A.; RIVKIN, S. G. Teacher quality. In: HANUSHEK, E.; WELCH, F. (Eds.) Handbook of the economics of education. Amsterdam, the Netherlands: Elsevier, p. 10511078, 2006.

HARM, M.; SEIDENBERG, M. S. Reading acquisition, phonology, and dyslexia: Insights from a connectionist model. Psychological Review, 106, p. 491-528, 1999.

HART, B.; RISLEY, T. R. Meaningful differences in the everyday experience of young American children. Baltimore, MD: Brookes. 1995.

HASKELL, T. R.; THORNTON, R.; MACDONALD, M. C. Experience and grammatical agreement: Statistical learning shapes number agreement production. Cognition, 114, 151, 2010.

HOFF, E. Interpreting the early language trajectories of children from low-SES and language minority homes: Implications for closing achievement gaps. Developmental Psychology, 49, p. 4-14, 2013.

HOOVER, W. A.; GOUGH, P. B. The simple view of reading. Reading and Writing, 2, p. 127$160,1990$.

HOXHALLARI, L.; VAN DAAL, V. H. P.; ELLIS, N. C. Learning to read words in Albanian: A skill easily acquired. Scientific Studies of Reading, 8, p. 153-166, 2004.

HULME, C.; SNOWLING, M. J. (Eds.) The science of reading: A handbook. Maldon, MA: Blackwell, 2005.

JENCKS, C.; PHILLIPS, M. America's next achievement test: Closing the black-white test score gap. American Prospect, 9, p. 44-53, 1998.

JOSHI, R. M.; AARON, P. G. (Eds.) Handbook of orthography and literacy. Mahwah, NJ: Lawrence Erlbaum Associates, 2006.

KAHNEMAN, D. Thinking, fast and slow. New York, NY: Farrar, Straus and Giroux, 2011. KATZ, L.; FROST, R. The reading process is different for different orthographies: The orthographic depth hypothesis. In FROST, R.; KATZ, L. (Eds.) Orthography, phonology, morphology, and meaning. Amsterdam, the Netherlands: Elsevier North Holland Press, p. 6784, 1992.

KRASHEN, S. More smoke and mirrors: A critique of the National Reading Panel report on fluency. The Phi Delta Kappan, 83, p. 119-123, 2001.

KUTNER, M.; et al. Literacy in everyday life: Results from the 2003 National Assessment of Adult Literacy. Washington, DC: National Center for Education Statistics, 2007.

LABOV, W. Language in the inner city: Studies in the Black English vernacular. Philadelphia, PA: University of Pennsylvania Press, 1972.

LESGOLD, A.; WELCH-ROSS, M. (Eds.) Improving adult literacy: Options for practice and research. Washington, DC: National Research Council, 2012.

LIBERMAN, I. Y.; et al. Phonetic segmentation and recoding in the beginning reader. In: REBER, A. S.; SCARBOROUGH, D. L. (Eds.) Toward a psychology of reading: The proceedings of the CUNY conference. Hillsdale, NJ: Erlbaum, p. 207-225, 1977.

LINDGREN, S. D.; DERENZI, E.; RICHMAN, L. C. Cross-national comparisons of developmental dyslexia in Italy and the United States. Child Development, 56, p. 1404- 1417, 1985.

LONIGAN, C. J.; SHANAHAN, T. Developing early literacy: Report of the National Early Literacy Panel. Executive summary. A scientific synthesis of early literacy development and implications for intervention. Washington, DC: National Institute for Literacy, 2009.

MAGNUSON, K. A.; DUNCAN, G. J. The role of family socioeconomic resources in the black-white test score gap among young children. Developmental Review, 26, p. 365-399, 2006.

MANN, H. Seventh annual report. Boston, MA: Dulton \& Wentworth, 1844. 
MANN, H. Twelfth annual report. The public and the school: Horace Mann on the education of freemen, 79-112. Boston, MA: Lee and Shepard, 1848.

MCCARDLE, P.; SCARBOROUGH, H. S.; CATTS, H. W. Predicting, explaining, and preventing children's reading difficulties. Learning Disabilities Research \& Practice, 16, p. 230239, 2001.

MIRKOVI'C, J.; MACDONALD, M. C.; SEIDENBERG, M. S. Where does gender come from? Evidence from a complex inflectional system. Language and Cognitive Processes, 20, p. 139-168. 2004.

MIRKOVI'C, J.; SEIDENBERG, M. S.; JOANISSE, M. F. Rules vs. statistics: Insights from a highly inflected language. Cognitive Science, 35, p. 638-681, 2011.

MOATS, L. Whole language hijinks. Thomas B. Fordham Institute. Disponível em:

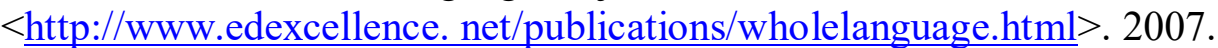

MOJE, E. B.; LUKE, A. Literacy and identity: Examining the metaphors in history and contemporary research. Reading Research Quarterly, vol. 44, no 4, p. 415-437, 2009.

NATION, K.; COCKSEY, J. The relationship between knowing a word and reading it aloud in children's word reading development. Journal of Experimental Child Psychology, 103, p. 296308, 2009.

NATIONAL ASSESSMENT OF EDUCATIONAL PROGRESS. Reading 2011, executive summary. Disponível em: <http://nces.ed. gov/nationsreportcard/pubs/main2011/2012457.asp>. 2011.

NATIONAL READING PANEL (NRP). Teaching children to read. Washington, DC: National Institute of Child Health and Human Development. Retrieved from $<$ http://www.nationalreadingpanel.org $>$. 2000.

OECD Publishing. PISA 2009 results: What students know and can do: Student performance in reading, mathematics and science, volume 1. Paris, France: Author. 2011.

PATTAMADILOK, C.; et al. How does learning to read affect speech perception? The Journal of Neuroscience, 30, p. 8435-8444, 2010.

PENNINGTON, B. F. From single to multiple deficit models of developmental disorders. Cognition, 101, p. 385-413, 2006.

PUGH, K. R.; et al. The relationship between phonological and auditory processing and brain organization in beginning readers. Brain \& Language, 2012.

RASINSKI, T.; YILDIRIM, K.; NAGELDINGER, J. Building fluency through the phrased text lesson. The Reading Teacher, 65, p. 252-255, 2011.

RAVITCH, D. Left behind: A century of battles over school reform. New York, NY: Simon and Schuster, 2000.

RAVITCH, D. The death and life of the great American school system: How testing and choice are undermining education. New York, NY: Basic Books. 2011.

RAYNER, K.; et al. How psychological science informs the teaching of reading. Psychological science in the public interest monograph, 2, p. 31-74. American Psychological Society, 2001.

REARDON, S. The widening academic achievement gap between the rich and the poor: New evidence and possible explanations. In: DUNCAN, G. J.; MURNANE, R, J. (Eds.) Whither opportunity? Rising inequality, schools, and children's life chances. New York, NY: Russell Sage Foundation, p. 91-116, 2011.

RICHARDSON, E. African American literacies. In: STREET, B.; HORNBERGER, N. H. (Eds.) Encyclopedia of language and education. $2^{\text {a }}$ ed., vol. 2: Literacy. New York, NY: Springer, p. 335-346, 2008.

RICKFORD, J. R. African American vernacular English: Features, evolution, educational implications. Oxford, England: Blackwell, 1999.

RICKFORD, J. R.; RICKFORD, R. J. Spoken soul: The story of Black English. New York, NY: Wiley, 2000. 
RICKFORD, J. R.; SWEETLAND, J.; RICKFORD, A. E. African American English and other vernaculars in education: A topic-coded bibliography Journal of English Linguistics, 32, p. 230320, 2004.

ROSE, J. Independent review of the teaching of early reading: Final report. London: England: Department for Education and Skills. Disponível em: $<$ www.standards.dfes.gov.uk/phonics/rosereview>. 2006.

SCRIBNER, S.; COLE, M. The psychology of literacy. Cambridge, MA: Harvard University Press, 1981.

SEIDENBERG, M. S. Language acquisition and use: Learning and applying probabilistic constraints. Science, 275, p. 1599-1604, 1997.

SEIDENBERG, M. S. Politics (of reading) makes strange bedfellows. Perspectives on Language and Literacy, Summer, p. 9-11, 2012.

SEIDENBERG, M. S. Reading in different writing systems: One architecture, multiple solutions. In: MCCARDLE, P.; REN, J.; TZENG, O. (Eds.) Dyslexia across languages: Orthography and the gene-brain-behavior link. Baltimore, MD: Paul Brooke Publishing, 2011.

SEIDENBERG, M. S. What happened to reading. New York, NY: Basic Books. (Manuscript in preparation), 2013.

SEIDENBERG, M. S.; MCCLELLAND, J. L. A distributed, developmental model of word recognition and naming. Psychological Review, 96, p. 523-568, 1989.

SMITH, F. Understanding reading: A psycholinguistic analysis of reading and learning to read. New York, NY: Holt, Rinehart \& Winston, 1971.

SNOW, C. E.; BURNS, M. S.; GRIFFIN, P. (Eds.) Preventing reading difficulties in young children. Washington, DC: National Academies Press, 1998.

SNOW, C. Reading for understanding: Toward an R\&D program in reading comprehension.

RAND Corporation report. Disponível em: $<$ http://www.rand.org/content/dam/rand/pubs/monograph_reports/2005/MR1465.pdf>. 2002.

SNOW, C.; et al. Unfulfilled expectations: Home and school influences on literacy. Cambridge, MA: Harvard University Press, 1991.

SNOWLING, M. J.; HAYIOU-THOMAS, M. E. The dyslexia spectrum: Continuities between reading, speech, and language impairments. Topics in Language Disorders, 26, p. 110-126, 2006.

SNOWLING, M.; HULME, C. The nature and classification of reading disorders: A commentary on proposals for DSM-5. Journal of Child Psychology and Psychiatry (prepublished online), 2011,

STANOVICH, K. E. Toward an interactive-compensatory model of individual differences in the development of reading fluency. Reading Research Quarterly, 16, p. 32-71, 1980.

TERRY, N. P. Dialect variation and phonological knowledge: Phonological representations and metalinguistic awareness among beginning readers who speak nonmainstream American English. Applied Psycholinguistics. In press.

TERRY, N. P.; SCARBOROUGH, H.S. The phonological hypothesis as a valuable framework for studying the relation of dialect variation to early reading skills. In: BRADY, S.; BRAZE, D.; FOWLER, C. (Eds.) Explaining individual differences in reading: Theory and evidence. New York, NY: Taylor \& Francis, p. 97-117, 2011.

THOMPSON, C. A.; CRAIG, H. K.; WASHINGTON, J. A. Variable production of African American English across oracy and literacy contexts. Language, Speech, and Hearing Services in Schools, 35, 269, 2004.

TOBIAS, S., DUFFY, T. M. (Eds.). Constructivist theory applied to instruction: Success or failure? New York, NY: Routledge, Taylor and Francis, 2009. 
UNITED STATES GOVERNMENT ACCOUNTABILITY OFFICE. Poverty in America. Report GAO-07-344. Washington, DC: Author. Disponível em: $<$ http://www.gao.gov/products/GAO-07-344>. 2007.

VANNEMAN, A.; et al. Achievement gaps: How black and white students in public schools perform in mathematics and reading on the national assessment of educational progress. Statistical Analysis Report. NCES 2009-455. Washington, DC: National Center for Education Statistics, 2009.

WASHINGTON, J. A.; PATTON TERRY, N.; SEIDENBERG, M. S. (in press). Language variation and literacy learning: The case of African American English. In: STONE, C. A.; SILLIMAN, E. R.; EHREN, B. J. APEL, K. (Eds.) Handbook of language and literacy: Development and disorders, $2^{\mathrm{a}}$ ed. New York: The Guilford Press.

WASHINGTON, J. Issues in assessing the language abilities of African American children. In: KAHMI, A.; POLLACK, K.; HARRIS, J. (Eds.) Communication development and disorders in African American children. Baltimore, MD: Paul H. Brookes, 1996.

WILLIS, J. Engaging the whole child: The neuroscience of joyful education, educational leadership. Disponível em: $\quad \underline{\text { http://www.ascd.org/publications/educational- }}$ leadership/summer07/vol64/num09/The-Neuroscience-of-JoyfulEducation.aspx >. 2007.

WOLFRAM, W.; SCHILLING-ESTES, N. American English: Dialects and variation (2nd edition). Malden, MA: Blackwell, 2006. 